\title{
ANZUELOS, FÍBULAS, PENDIENTES Y CUCHILLOS: UNA MUESTRA DE LA PRODUCCIÓN DE LOS TALLERES METALÚRGICOS DE LA FONTETA
}

\author{
HOOKS, FIBULAE, EARRINGS AND KNIVES: A SAMPLE OF THE OUTPUT OF THE METALLURGY \\ WORKSHOPS OF LA FONTETA
}

\author{
ALFREDO GONZÁLEZ PRATS \\ Universidad de Alicante
}

Una de las actividades más notorias y sobresalientes desarrolladas en la colonia fenicia de La Fonteta fue sin duda la transformación de diversos minerales metálicos para la obtención de objetos de cobre, de hierro, de plomo y de plata (González Prats, 1999; González Prats y Renzi, 2003, 157).

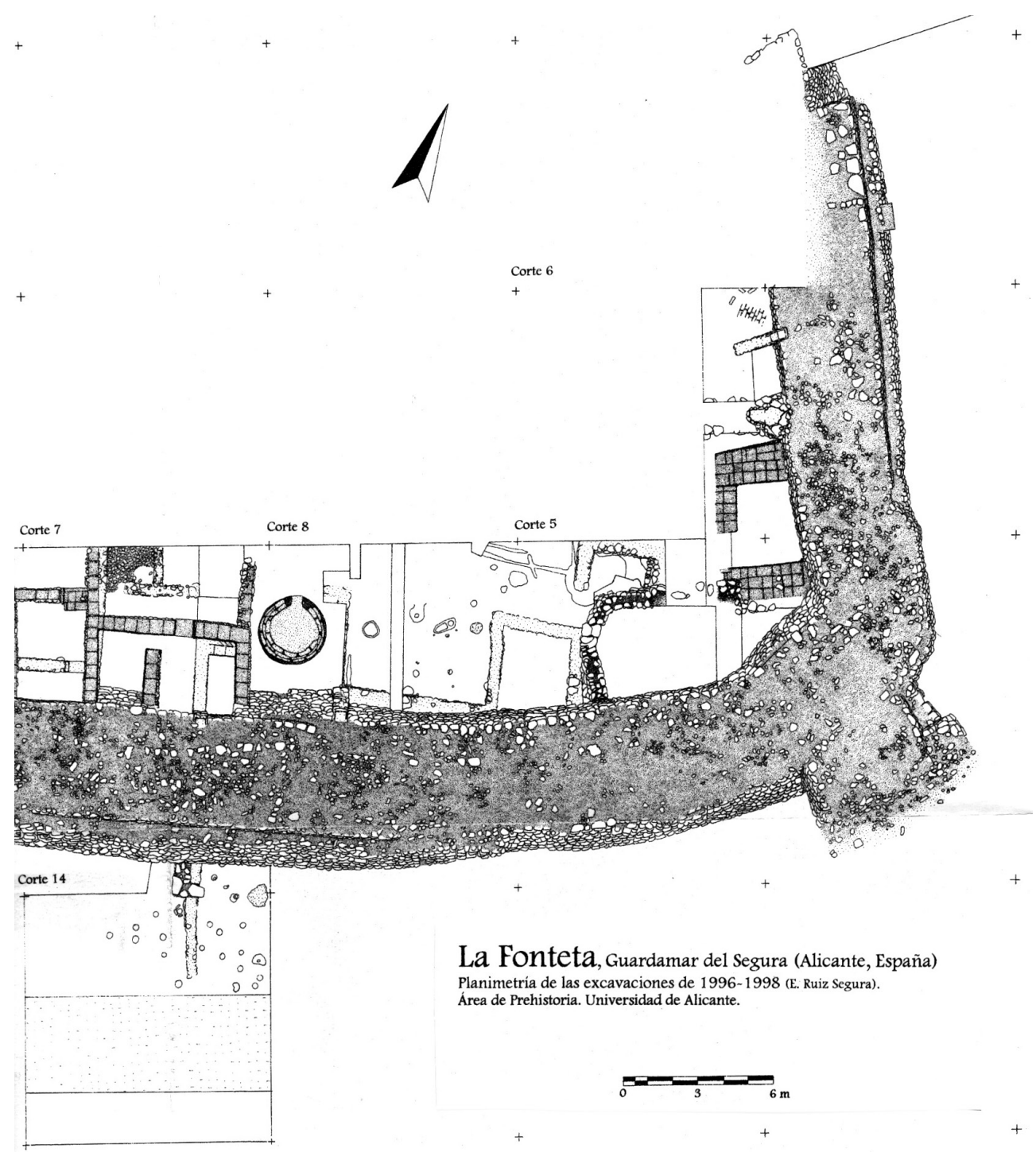

Figura 1: Zona metalúrgica de Fonteta I y II indicada por sombreado gris.Tamaño de las cuadrículas 10 x $10 \mathrm{~m}$. 


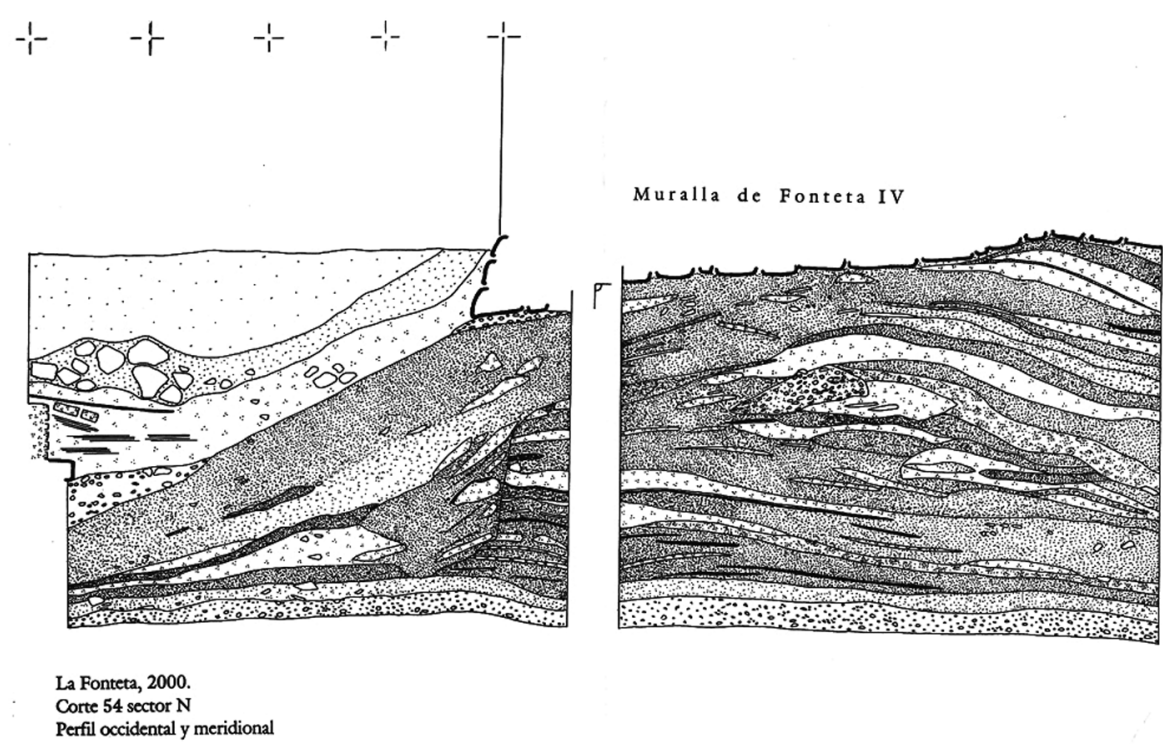

Figura 2: Sección de los depósitos metalúrgicos en el Corte 54, pisados por la muralla de Fonteta IV.

Aparte de la elaboración de hachas o cinceles planos registrada a través de los diversos moldes de arenisca aparecidos en la campaña de 1997, que pertenecían a un taller de Fonteta III (González Prats y Ruiz Segura, 1999), queremos llamar ahora la atención sobre determinadas piezas de bronce y hierro por su reiterada presencia entre los materiales recuperados en las escombreras metalúrgicas correspondientes a los momentos más arcaicos de la instalación de la colonia de Guardamar del Segura.

Estas escombreras, registradas en los Cortes $5 \mathrm{~N}$, 54 y 1 (Fig. 1), forman un espeso depósito de cerca de dos metros constituido por sucesivos vertidos de los restos de las actividades metalúrgicas e integran paredes y restos de los pequeños hornos, reconstruidos y destruidos constantemente, toberas de tipos cilíndrico y prismático con una o dos perforaciones, crisoles de arcilla con adherencias metálicas junto a un abundantísimo material fragmentario que ha deparado cientos de objetos metálicos y los restos habituales del material arqueológico no metalúrgico.
Estos depósitos vierten directamente sobre la línea antigua de costa, como se detectó en los Cortes 54 y 1 , demostrando que se eligió un punto seguramente alejado del área central del asentamiento para evitar las molestias derivadas de esta actividad industrial. La serie estratigráfica abarca desde el estrato $\mathrm{B} 1$ al estrato B13, y se corresponde con las fases II y I del yacimiento. Estos escoriales quedarían registrados igualmente en el Corte $5 \mathrm{~N}$ de 1998 con la serie estratigráfica B8-B12-C (Fig. 2).

La datación de estas series viene de la mano de la presencia de cerámicas griegas geométricas: en la serie superior, fragmentos de kotylai protocorintias con $\mathrm{y}$ sin fondo estrellado, y, en la serie inferior, fragmentos de copas de tipo Thapsos (Fig. 3). Robustas ánforas áticas de tipo SOS acompañan estas producciones. Es decir, cerámicas que arrojan unas fechas que abarcarían desde mediados del siglo VIII al primer cuarto del siglo VII a.C., datación que venimos aplicando a las fases I y II de La Fonteta.
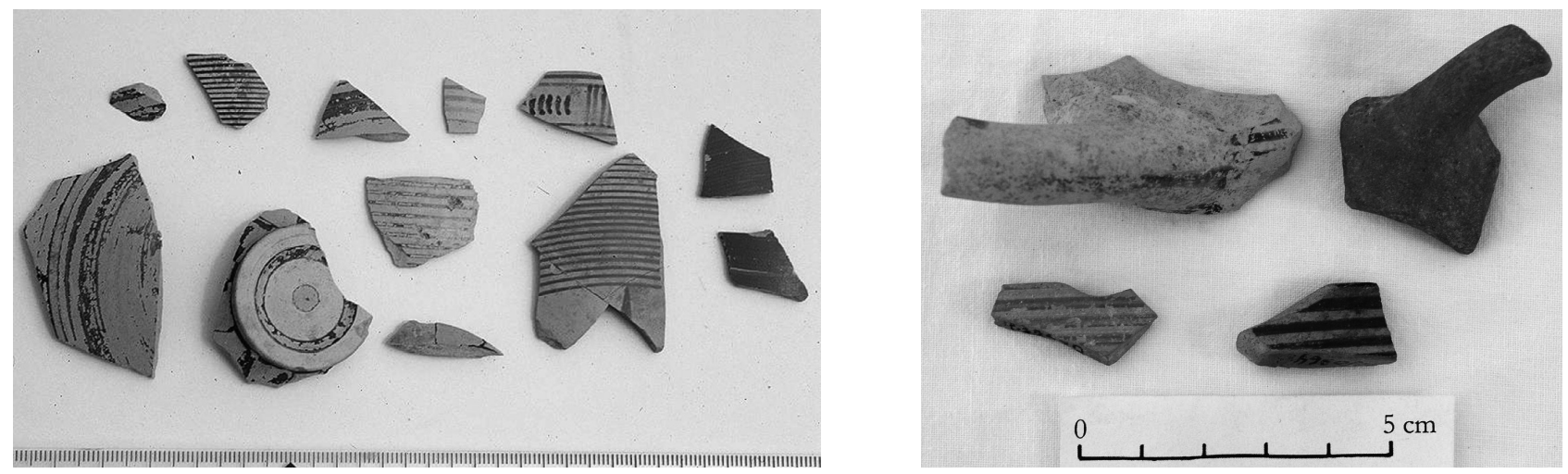

Figura 3: Cerámicas protocorintias y copas Thapsos de los Cortes 25, 5N y 54. 


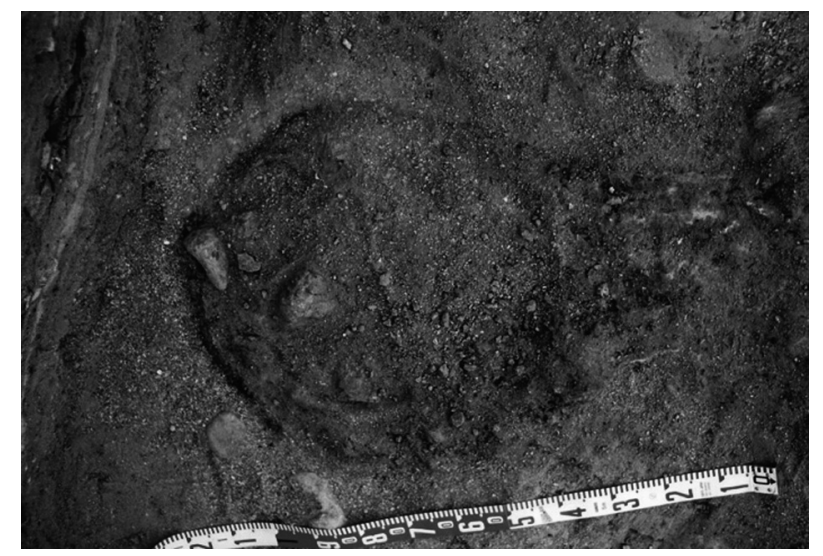

Figura 4: Horno metalúrgico de Fonteta I en la base del depósito del Corte 54 norte, sobre la playa del siglo VIII a.C.

Hemos elegido algunos de los objetos metálicos singulares que nos han proporcionado tales depósitos ante la seguridad o sospecha de que fueron elaborados en dichos talleres (Fig. 4), en cuyos depósitos se encuentran además numerosos objetos de carácter utilitario y suntuario que se recogen en el capítulo correspondiente de la monografía que estamos ultimando.

\section{ANZUELOS}

Es lógica la presencia de este tipo de artilugio de pesca en un yacimiento plenamente costero con una explotación pesquera que debió abastecer las necesidades cotidianas de la colonia y posiblemente la exportación de pescado en salazón hacia el hinterland tanto en cajas de madera como en tinajas cerámicas de boca ancha, como los ejemplares de tipo E13 de Peña Negra (González Prats, 1983), con dos y cuatro asas geminadas, en cuyo interior se han hallado escamas de pescado. Economía pesquera que responde plenamente a la fama que tuvo en la Antigüedad el mundo fenicio, lo que se comprueba en el ajuar de algunas tumbas de la necrópolis reciente de Toscanos (Maass-Lindemann, 1995, 154).

Todos los ejemplares hallados son de bronce, excepto el núm. 13025, que es de hierro. La pieza núm. 42286 nos da la clave de su elaboración y delata su fabricación local. Es un vástago de 2,5 mm de sección circular, obtenido en molde de varillas, cuyos extremos apuntados se han doblado con una suerte de tenazas, y en la punta se acondiciona mediante una lima la barba. Una vez hecho este proceso no hay mas que partir el vástago por la mitad, y disponemos de dos anzuelos. No hemos observado la presencia de ojal alguno para pasar el sedal, en cambio casi todos ofrecen un adelgazamiento de la pata donde se anudaría aquél, en ocasiones facilitado por ranuras realizadas para ello. La ingente cantidad de fragmentos de varillas circulares que arrojan los mismos diámetros, hallada en los depósitos metalúrgicos, puede ser ilustrativa de la fabricación constante de estas piezas mediante el procedimiento descrito.

Comoquiera que las dimensiones han sido tomadas de las piezas sin limpiar, es preciso contemplar una reducción de las secciones y de las aperturas de los ejemplares analizados, de tal manera resulta prudente aplicar a ambas medidas un valor de reducción en torno a 0,5-1 mm. Los ejemplares procedentes de los estratos de arena, sobre todo aquellos procedentes del depósito de base de Fonteta I, presentan adheridos numerosos gránulos de cuarzo y sílice que no se han eliminado en pro de la integridad de las piezas.

Aprovechamos para incluir también aquellos ejemplares procedentes de otras fases del yacimiento, ya que muestran las mismas características a lo largo de toda la secuencia, y así el investigador podrá hacerse una idea general de sus morfologías. La longitud de los ejemplares mejor conservados oscila entre 20 y $29 \mathrm{~mm}$, su abertura entre 10 y $16 \mathrm{~mm}$ y los filamentos, siempre circulares, ofrecen diámetros entre 2 y $4,5 \mathrm{~mm}$, sin reducir las medidas. A efectos comparativos, los anzuelos de Fonteta corresponderían a los tipos actualmente definidos que van del 4/0 al 7/0 y que son aptos para la pesca de corvina, gatuzo, anchoa, mero, lenguado, róbalo, congrio o bonito. En nuestras excavaciones hemos podido documentar otolitos de corvina, y el material para el estudio ictiológico está siendo llevado a cabo por Ricard Marlasca. Los análisis ictiológicos publicados por el equipo hispano-francés que excavó parte del yacimiento ilustran las especies marinas consumidas: besugo, salpa, dorada, boga, sargo, pagel, chucla, raya, cabrilla/mero, musola, caballa, lubina y esturión, al lado de un constante abastecimiento de barbo del río Segura (Sternberg, 2007, 372 ss.). Nuestros colegas hispano-franceses han presentado cuatro anzuelos de bronce procedentes de sus fases II, III y Vb (Le Meaux-Sánchez, 2007, figs. 253, 254 y 260).

Los hallazgos de La Fonteta encuentran su parangón morfológico y cronológico en la fase B1a del Morro de Mezquitilla (Mansel, 2000, fig. 5), datada en la segunda mitad del siglo VIII AC.

\section{ANZUELOS PROCEDENTES DE LOS DEPÓSITOS METALÚRGICOS (Figs. 5-7)}

21145. Anzuelo. Bronce. Longitud: $20 \mathrm{~mm}$; abertura: $12,2 \mathrm{~mm}$; sección: $2,7 \mathrm{~mm}$. Procedencia estratigráfica: 54N-B12. Fase I (760-720 aC)

42076. Anzuelo incompleto. Bronce. Longitud: 10,4 mm; sección: 3,5 mm. PE: 54SW-B5f. Fase I.

42148. Anzuelo incompleto. Bronce. Longitud: 14,3 mm; abertura: 9,8 mm. sección: 2,6. PE: 54SWB5f. Fase I.

42185. Anzuelo incompleto. Bronce. Longitud: 14,2 $\mathrm{mm}$; sección: 2,6 mm. PE: 54S-A5b. Fase I.

55303. Anzuelo incompleto. Bronce. Longitud: 26,2 mm; abertura: $12,4 \mathrm{~mm}$; sección: 2,5 mm. PE: $1 \mathrm{~W}$ B4. Fase I. 

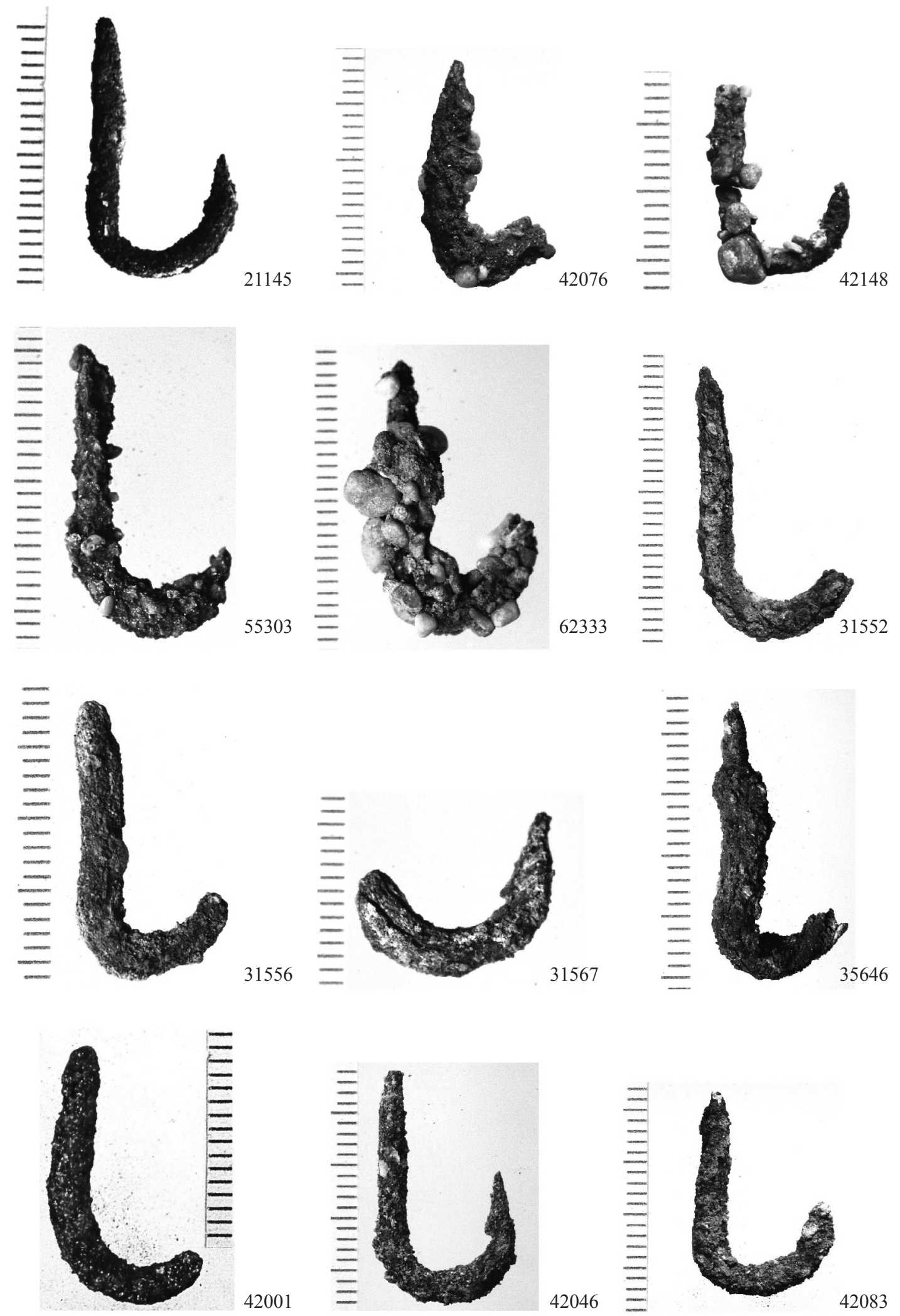

Figura 5: Anzuelos de los depósitos metalúrgicos de Fonteta I y II (760-670AC) 

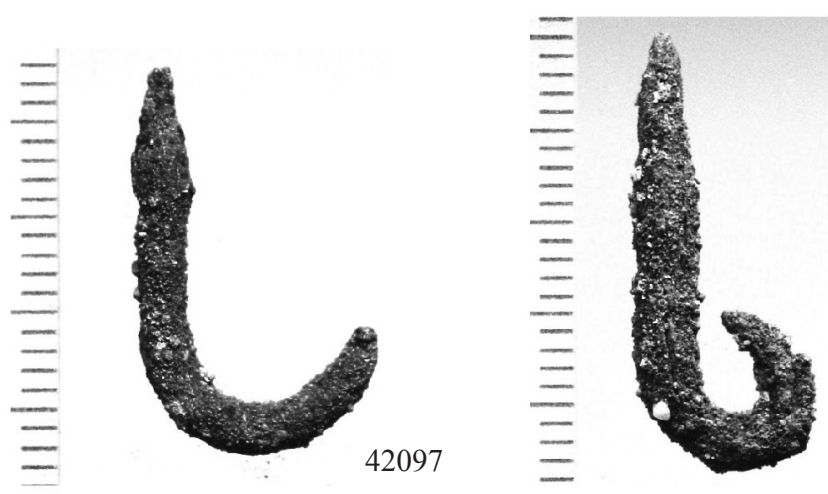

42112
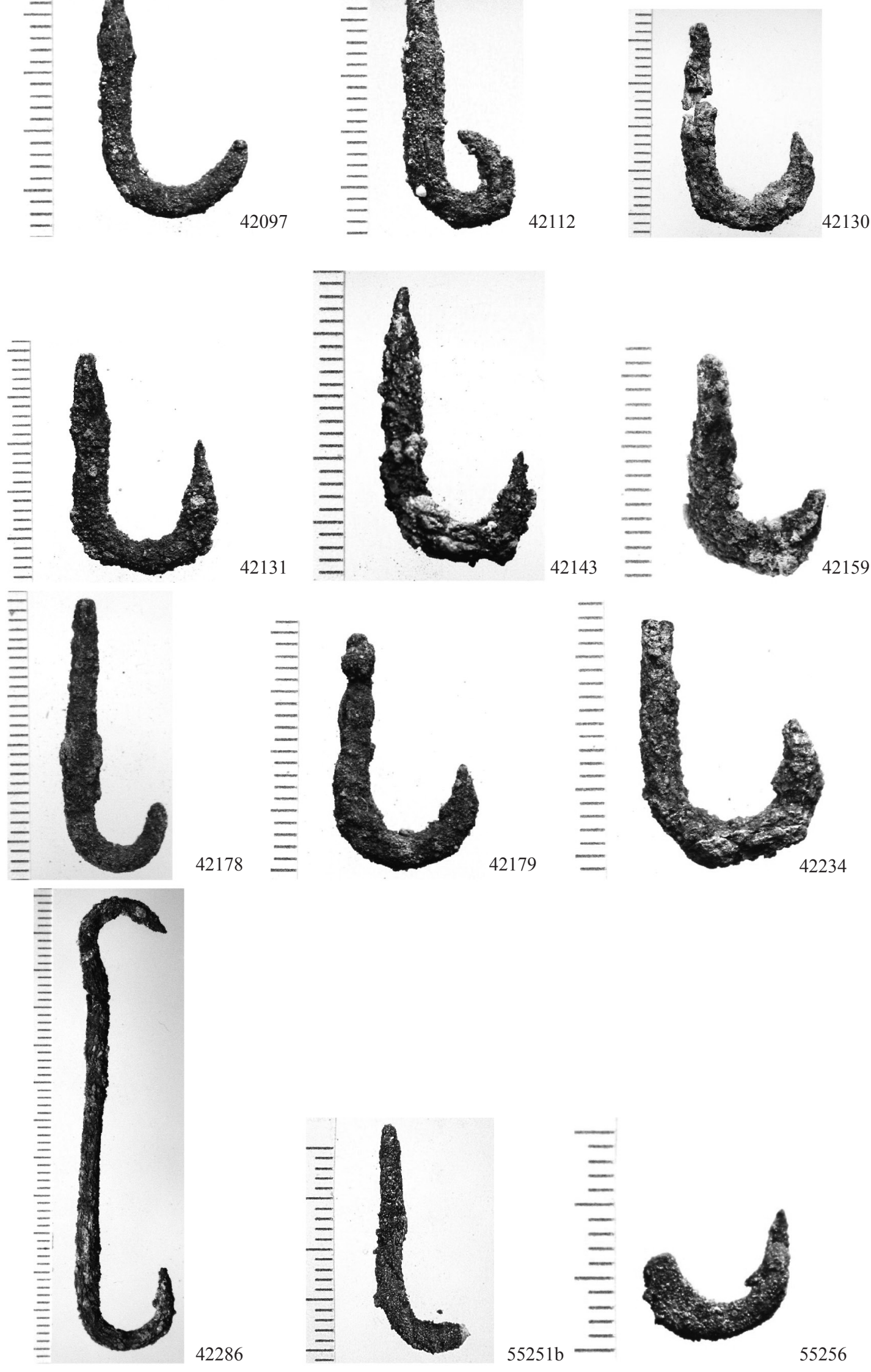

Figura 6: Anzuelos de los depósitos metalúrgicos de Fonteta II. 

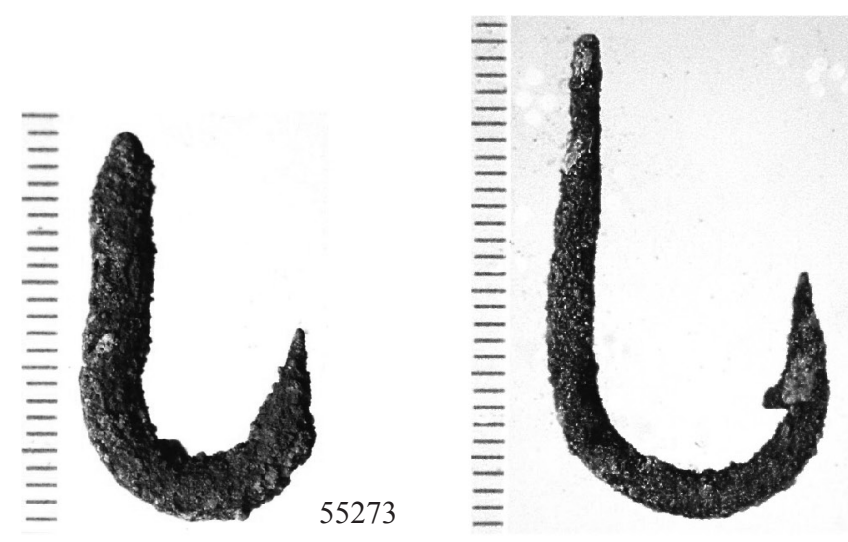

55276
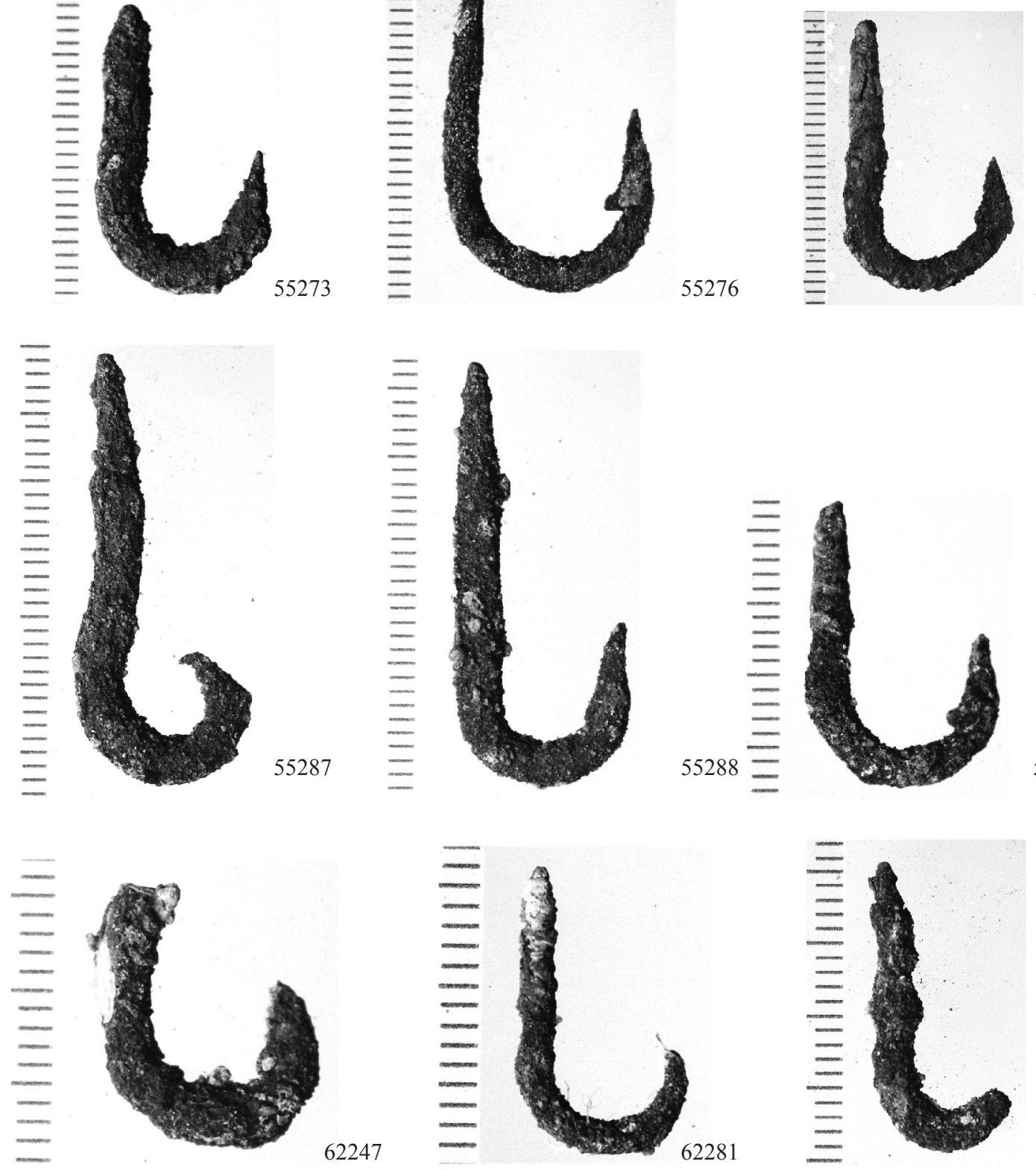

Figura 7: Anzuelos de los depósitos metalúrgicos de Fonteta II.

55321. Anzuelo. Bronce. Longitud: $19 \mathrm{~mm}$; abertura: 10,9 mm; sección: 4 mm. PE: 1W-B3c/4. Fase I.

62333. Anzuelo. Bronce. Longitud: $24,4 \mathrm{~mm}$; abertura: $13,5 \mathrm{~mm}$; sección: 3,8 mm. PE: 1N-B4. Fase I. 62334. Anzuelo incompleto. Bronce. Longitud: 14,5 $\mathrm{mm}$; abertura 11,1 mm; sección: 3,8 mm. PE: $1 \mathrm{~N}-$ B4. Fase I.

21144. Anzuelo incompleto. Bronce. Longitud: 24 mm; sección: 3 mm. PE: 5N-B9d. Fase II (720-670 $\mathrm{aC})$.
25030. Anzuelo incompleto. Bronce. Longitud: 25 mm; sección: $2 \mathrm{~mm}$. PE: 5N-B9cd. Fase II.

25031. Anzuelo incompleto. Bronce. Longitud: 25 mm; sección: 2,5 mm. PE: 5N-B9cd. Fase II.

31552. Anzuelo incompleto. Bronce. Longitud: 26,5mm; sección: $6 \mathrm{~mm}$. PE: 5N-B9a. Fase II.

31556b. Anzuelo incompleto. Bronce. Longitud: 19,6 mm; sección: 2,7 mm. PE: 5N-B8de. Fase II.

31567. Curva de anzuelo. Bronce. Abertura: 14,6 mm; sección: 3,1 mm. PE: 5N-B10ab. Fase II. 
35646. Anzuelo incompleto. Bronce. Longitud: 22,8 mm; sección: 5,3 mm. PE: 54-B10. Fase II.

42001. Anzuelo incompleto. Bronce. Longitud: 25 mm; sección: 2,5 mm. PE: 54-B4c. Fase II.

42046. Anzuelo. Bronce. Longitud: 21,5 mm; abertura: $13 \mathrm{~mm}$; sección: 2,5 mm. PE: 54-B3c. Fase II.

42083. Anzuelo. Bronce. Longitud: $18,9 \mathrm{~mm}$; abertura: $13 \mathrm{~mm}$; sección: 2,9 mm. PE: 54N-B8. Fase II.

42097. Anzuelo incompleto. Bronce. Longitud: 20,3 mm; sección: 2,5 mm. PE: 54S-B1/3. Fase II.

42112. Anzuelo con punta doblada. Bronce. Longitud: 24,1 mm; sección: 3,4 mm. PE: 54N-B8. Fase II.

42130. Anzuelo. Bronce. Longitud: 25,4 mm; abertura: 14,5 mm; sección: 3,2 mm. PE: 54N-B10. Fase II.

42131. Anzuelo. Bronce. Longitud: 24,1 mm; abertura: $15 \mathrm{~mm}$; sección: 3,3 mm. PE: 54N.B3de. Fase II.

42143. Anzuelo. Bronce. Longitud: 22,6 mm; abertura: $11 \mathrm{~mm}$; sección: 3,2 mm. PE: 54N-B9. Fase II.

42159. Anzuelo incompleto. Bronce. Longitud: 16 mm; sección: 3,3 mm. PE: 54S-A5a. Fase II.

42178. Anzuelo incompleto. Bronce. Longitud: 28,1 mm: sección: 3,4 mm. PE: 54N-B1/3d. Fase II.

42179. Anzuelo. Bronce. Longitud: $20 \mathrm{~mm}$; abertura: $12 \mathrm{~mm}$; sección: 2,5 mm. PE: 54N-B1/3d. Fase II.

42234. Anzuelo. Bronce. Longitud: 19,2 mm; abertura: 13,8 mm; sección: 3 mm. PE: 54S-B3. Fase II.

42284. Anzuelo. Bronce. Longitud: $16,5 \mathrm{~mm}$; abertura: 12,5; sección: 3,3 mm. PE: 54N-B3e. Fase II.

42286. Doble anzuelo en proceso de fabricación, sin dividir. Bronce. Longitud: 59 ( 2 x 29,5) mm; abertura: 13,6 mm; sección: 2,5 mm. PE: 54N-B6. Fase II.

55251b. Anzuelo incompleto. Bronce. Longitud: 23 mm; sección: 2 mm. PE: 1W-B2b. Fase II.

55256. Curva de anzuelo. Bronce. Abertura: 10,5 mm; sección: $2 \mathrm{~mm}$. PE: 1W-B1. Fase II.

55273. Anzuelo. Bronce. Longitud: 23,1 mm; abertura: 13,9 mm; sección: 3,8 mm. PE: 1WC-B2c. Fase II.

55276. Anzuelo. Bronce. Longitud: 29,2 mm; abertura: 16,6 mm; sección: 2,8 mm. PE: 1W-B2a. Fase II.

55277. Anzuelo. Bronce. Longitud: 26,3 mm; abertura; 16,5 mm; sección: 3,1 mm. PE: 1W-B2a. Fase II.

55287. Anzuelo. Bronce. Longitud: $31,7 \mathrm{~mm}$; abertura: 13,6 mm; sección: 3,6 mm. PE: 1W-B1. Fase II.

55288. Anzuelo. Bronce. Longitud: $30,3 \mathrm{~mm}$; abertura: $12,9 \mathrm{~mm}$; sección: 3,2 mm. PE: $1 \mathrm{~W}-\mathrm{B} 1$.

55309. Anzuelo. Bronce. Longitud: 20,3 mm; abertura: 13,4 mm; sección: 3,2 mm. PE: 1W-B1. Fase II.

62246. Anzuelo. Bronce. Longitud: 19,6 mm; abertura: 11,3 mm; sección: 3,3 mm. PE: 1N-B3. Fase II.

62247. Anzuelo incompleto. Bronce. Longitud: 14,3 mm; abertura: 10,9 mm; sección: 2,8 mm. PE: 1NB3. Fase II.

62281. Anzuelo. Bronce. Longitud: 14,6 mm; abertura: 9,1; sección: 1,6 mm. PE: 1-B1. Fase II.

62282. Anzuelo incompleto. Bronce. Longitud: 20,1 mm; sección: 2,5 mm. PE:1-B1. Fase II.

62298. Anzuelo. Bronce. Longitud: 10,2 mm; abertura: 10,6 mm; sección: 2,7 mm. PE: 1N-B2a. Fase II.
62326. Anzuelo. Bronce. Longitud: 28,4 mm; abertura: 14,1 mm; sección: 2,3 mm. PE: 1N-B2a. Fase II. 62327. Anzuelo. Bronce. Longitud: $19 \mathrm{~mm}$; abertura: 10,7 mm; sección: 2,8 mm. PE: 1N-B2a. Fase II.

ANZUELOS HALLADOS EN EL RESTO DE LA SECUENCIA (Fig. 8)

10098. Anzuelo. Bronce. Longitud: 20,2 mm; abertura: $12,8 \mathrm{~mm}$; sección: 2,8 mm. PE: 14-B9. Fase III $(670-635 \mathrm{aC})$.

13021. Anzuelo. Bronce. Longitud: $21 \mathrm{~mm}$; abertura: 14 mm; sección 3,1 mm. PE: 14NW-B9c. Fase III.

25063. Anzuelo incompleto. Bronce. Longitud: 23,2 mm; sección: 2,7 mm. PE: 8BC-B11ab. Fase III.

25077. Anzuelo incompleto. Bronce. Longitud: 23 mm; sección: 3 mm. PE: 5AB-B9. Fase III.

31547b. Anzuelo incompleto. Bronce. Longitud: 31,4 mm; sección: 3,9 mm. PE: 5Asur-B9b. Fase III.

31561. Anzuelo incompleto. Bronce. Longitud: 26,6 mm; abertura: $15,1 \mathrm{~mm}$; sección: $3,8 \mathrm{~mm}$. PE: $5 \mathrm{~N}-$ A5. Fase V (620-580 aC).

31562. Anzuelo incompleto. Bronce. Longitud: 23,4; abertura: 12,5 mm; sección: 3,2 mm. PE: 5N-A5. Fase V.

10103. Anzuelo incompleto. Bronce. Longitud: 24 $\mathrm{mm}$; abertura: $11 \mathrm{~mm}$; sección: $2,4 \mathrm{~mm}$. PE: 8CA3b. Fase VI (580-560 aC).

10104. Anzuelo concrecionado con el ejemplar 10105. Bronce. Longitud: 28,5 mm; abertura: $12 \mathrm{~mm}$; sección: 3,8 mm. PE: 8C-A3b. Fase VI.

10105. Anzuelo concrecionado con el ejemplar 10104. Bronce. Longitud: 25,3 mm; abertura: $12 \mathrm{~mm}$; sección: $3 \mathrm{~mm}$. PE: 8C-A3b. Fase VI.

10106. Anzuelo. Bronce. Longitud: $22 \mathrm{~mm}$; abertura: $12 \mathrm{~mm}$; sección: $3 \mathrm{~mm}$. PE: 8C-A3b. Fase VI.

13001. Anzuelo. Bronce. Longitud: $17 \mathrm{~mm}$; abertura: 9,2 mm; sección: 2 mm. PE: 8B-A3. Fase VI.

13025. Anzuelo incompleto. Hierro. Longitud: 30 mm; sección: 5,4 mm. PE: 8B-A3b. Fase VI.

15022. Anzuelo. Bronce. Longitud: $19 \mathrm{~mm}$; abertura: 10,8 mm; sección: 3,3 mm. PE: 8BC-A3. Fase VI.

21138. Anzuelo. Bronce. Longitud: $23,3 \mathrm{~mm}$; abertura: $11 \mathrm{~mm}$; sección, 2,5 mm. PE: 5B-A2b. Fase VI.

25098. Anzuelo incompleto. Bronce. Longitud: 17 mm; sección: 2 mm. PE: 5C-A3. Fase VI.

\section{FÍBULAS DE DOBLE RESORTE}

Dentro del conjunto de elementos metálicos hallados en las escombreras de los primeros talleres metalúrgicos han ido apareciendo de forma repetida fragmentos correspodientes a fíbulas del tipo de doble resorte, que marcan un horizonte cronológico en nuestra protohistoria peninsular íntimamente relacionado con los ámbitos fenicios y orientalizantes. 

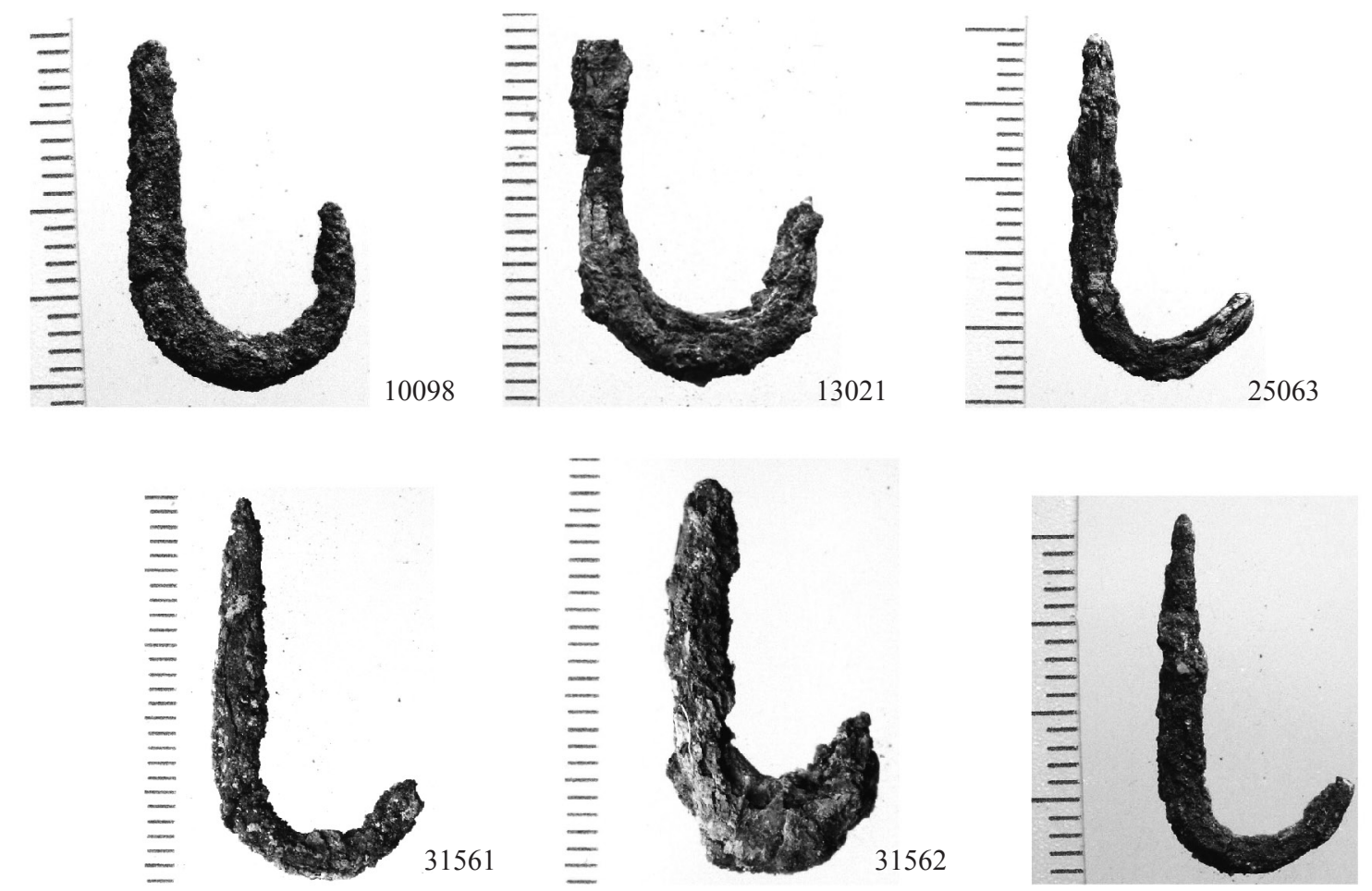

10103

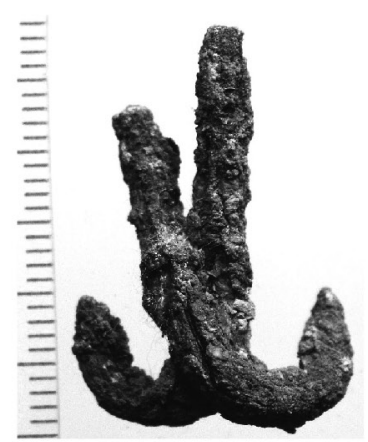

10104-10105
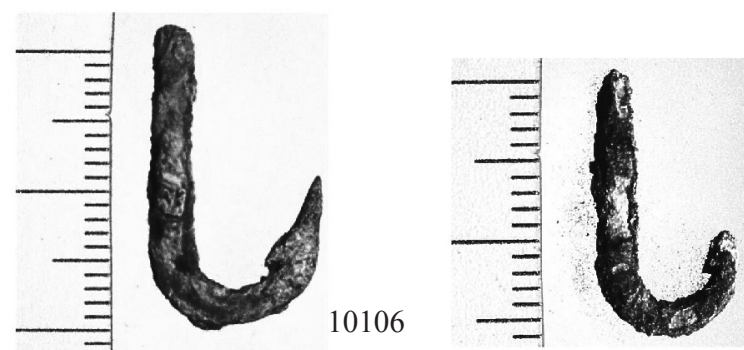

13001
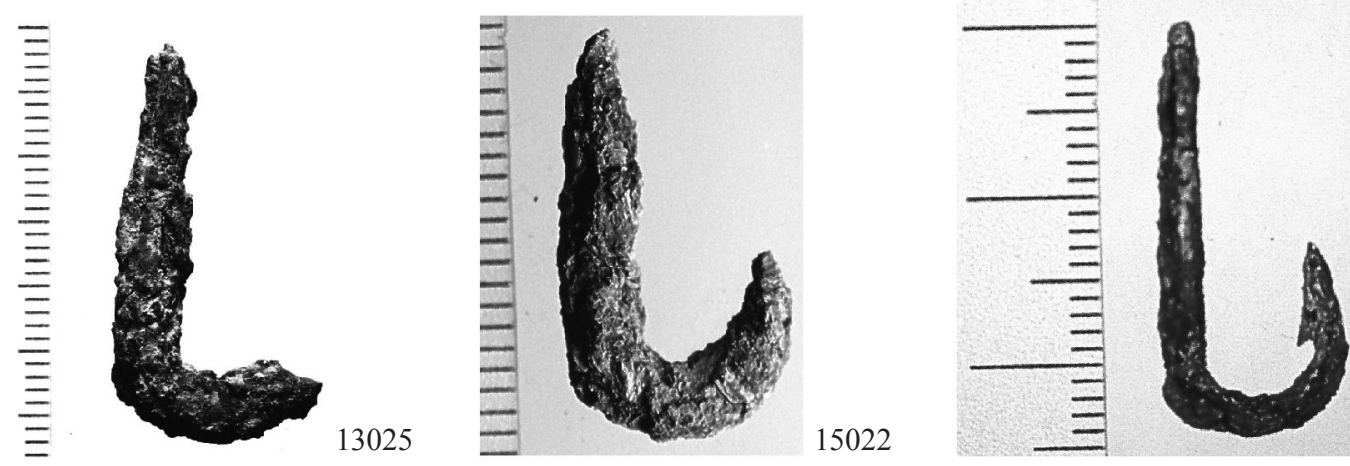

21138

Figura 8: Anzuelos de Fonteta III, V y VI. 
Llamó nuestra atención el hecho de la aparición de algunas mortajas que se presentaban planas, sin la torsión correspondiente para alojar el extremo de la aguja. Este detalle, y de nuevo las numerosas varillas de sección circular, omnipresentes y abundantísimas en el depósito, que arrojan diámetros similares a los filamentos con los que se fabrican las fíbulas de doble resorte y los anzuelos, nos inducen a sospechar otra de las elaboraciones metálicas propias.

$\mathrm{Su}$ elaboración es muy simple (Ruiz Delgado, 1986; 1987-88, 516; 1989): partiendo de un filamento de bronce de sección circular, en nuestro caso como en el de la mayoría de las fíbulas de este tipo peninsulares de semejante cronología, se realiza un acodamiento en el primer tramo reservado a la mortaja, sube la pata hasta un segundo acodamiento donde, utilizando otro vástago a modo de eje, se enrolla en él el filamento con cinco, seis o siete vueltas, generando el primer resorte, de donde se continúa con un puente hasta un nuevo giro para realizar el segundo resorte, de cuyo final se extiende el filamento, generando la aguja que cerrará en la mortaja correspondiente del pie.

Aprovechamos este trabajo para ofrecer, igualmente, aquellos ejemplares pertenecientes a otras fases de la secuencia y los otros tipos de fíbulas que se asocian a las fíbulas de doble resorte más evolucionadas y complejas, como son las fíbulas de resorte bilateral y puente de cinta, o algún ejemplar de fíbula de pivote, que pueden no haber sido elaboradas en los talleres de Fonteta. Nuestra propuesta de elaboración afecta en principio sólo a los ejemplares de doble resorte.

A propósito del resorte bilateral de una fíbula hallada en la tumba 100 de la necrópolis Jardín, y tomado como exponente del escaso registro hallado en tumbas fenicias, G. Maas-Lindemann duda de que las fibulas formaran parte de la indumentaria de la población fenicia (Maass-Lindemann, 1995, 152). Sin embargo, los hallazgos de Trayamar, Chorreras y Morro de Mezquiti1la (Mansel, 2000, fig. 4) o de la propia Cartago (Niemeyer y Docter et alii, 1998, 93) no deben minusvalorarse, por más que se pretenda adscribir las fíbulas de doble resorte al hinterland orientalizante al que, hasta hace poco, se vinculaban yacimientos hoy tan poco autóctonos como El Carambolo. La presencia de fíbulas en las tumbas de la necrópolis de Akhziv es indicativa del uso de estos imperdibles en la vestimenta fenicia (Mazar, 2001, fig. 17,4; 2004, fig. 115). Creo que precisamente la fíbula de doble resorte es un tipo generalizado tanto entre fenicios como entre la población autóctona orientalizante que adoptaba y adaptaba los usos coloniales.

ELEMENTOS DE FÍBULAS DE DOBLE RESORTE PROCEDENTES DE LOS DEPÓSITOS METALÚRGICOS Y FASES RELACIONADAS (Figs. 9-12)

15027. Resorte de 5 vueltas y arranque del puente. Bronce. Dimensiones: 11 x 13,5 mm. PE: 7CEB14. Fase I (760-720 aC).
4301. Mortaja plana y curvada. Bronce. Dimensiones: 33,2 x 8,6 mm. PE: 25B1-B9c. Fase II (720-670 $\mathrm{aC})$

31537. Mortaja. Bronce. Dimensiones: 22,6 x 7,3 mm. PE: 5N-B9c. Fase II.

31572. Mortaja. Bronce. Dimensiones: 24,3 x 4,3 mm. PE: 5N-B9d. Fase II.

42007. Resorte con tres espiras. Bronce. Dimensiones: $19 \mathrm{~mm}$. PE: 54N-B4bc. Fase II.

42010. Fragmentos de fíbula. Bronce. Dimensiones: 24 x 4,5 mm. PE: 54N-B5. Fase II.

42013. Fragmentos de fíbula con resorte de 6 espiras. Bronce. Filamento de 3,4 mm. PE: 54S-B1. Fase II.

42020. Fragmentos de fíbula. Bronce. Filamento de 6,2 mm. PE: 54-B4b. Fase II.

42023. Resorte con 5 espiras de fíbula. Bronce. Dimensiones: 17,8 x 7 mm. PE: 54-B3b. Fase II.

42036. Puente y resorte con tres espiras. Bronce. Dimensiones: 35 x 4 mm. PE: 54-B1. Fase II.

42092a. Mortaja plana. Bronce. Dimensiones: 18,8 x $12 \mathrm{~mm}$. PE: 54N-B6. Fase II.

42092b. Mortaja plana. Bronce. Dimensiones: 17,2 x $8,2 \mathrm{~mm}$. PE: 54N-B6. Fase II.

42101. Fragmento de resorte. Bronce. Dimensiones: 13,2 x 9,1 mm. PE: 54N-B3f. Fase II.

42117. Mortaja. Bronce. Dimensiones: 15 x 7,8 mm. PE: 54N-B8/9. Fase II.

42168. Mortaja y fragmento de pie. Bronce. Dimensiones: 25,4 x 4,6 mm. PE: 54S-B3/4. Fase II.

42183. Fragmentos de fíbula. Bronce. PE: 54S-B3/4. Fase II.

42191. Posible mortaja. Bronce. Dimensiones: 22,6 x 9,2 mm. PE: 54N-B3d. Fase II.

42194. Resorte con pie y mortaja. Bronce. Dimensiones: 27,6 x 3,4 mm. PE: 54S-B5b. Fase II/I.

42204. Mortaja. Bronce. Dimensiones: 19,1 x 10,4 mm. PE: 54S-B1. Fase II.

42262. Mortaja. Bronce. Dimensiones: 23,3 x 6,7 mm. PE: 54N-B9. Fase II.

55308. Mortaja. Bronce. Dimensiones: 21 x 5,7 mm. PE: 1W-B1. Fase II.

62252b. Mortaja. Bronce. Dimensiones: 21 x 9,5 mm. PE: 1N-B2a. Fase II.

62255b. Mortaja. Bronce. Dimensiones: 21 x 6,3 mm. PE: 1N-B2a. Fase II.

62262b. Mortaja. Bronce. Dimensiones: 16,5 x 5,9 mm. PE: 1-B1b. Fase II.

62265b. Mortaja. Bronce. Dimensiones: 28,8 x 12 mm. PE: 1N-B2a. Fase II.

62279. Fíbula incompleta con resorte de 5 espiras. Bronce. Longitud: $55,7 \mathrm{~mm}$. Sección filamento: 3,2 mm. PE: 1-B1. Fase II.

62284. Mortaja. Bronce. Dimensiones: 21,8 x 4,8 mm. PE: 1-B1. Fase II.

62295. Pie con mortaja y resorte. Bronce. Dimensiones: 37,3 x 35 mm. PE: 1N-B2a. Fase II.

62325. Resorte de 6 espiras y puente. Bronce. Dimensiones: 29,5 x 15,9. PE: 1N-B2a. Fase II. 

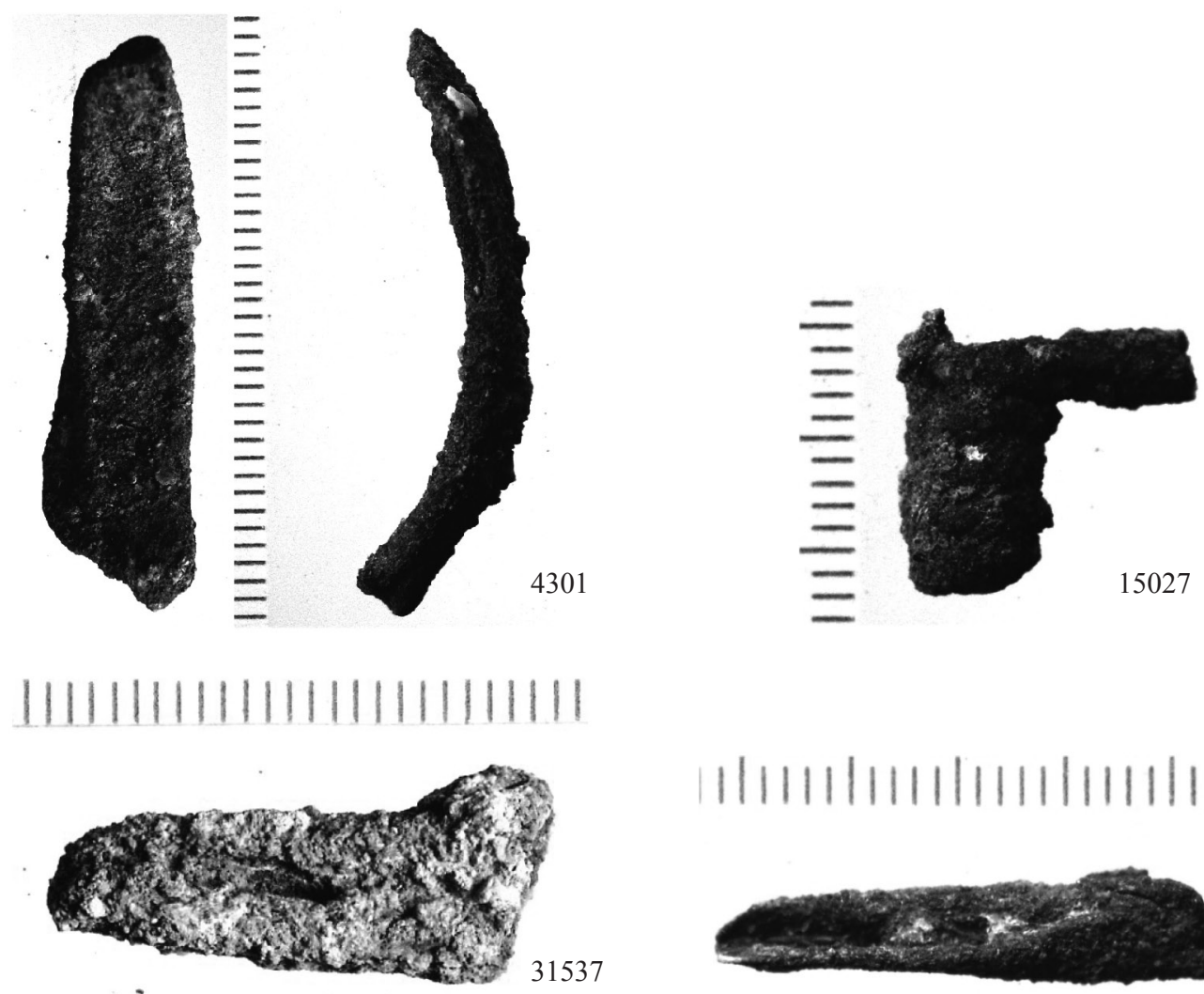

11111111111111111111111
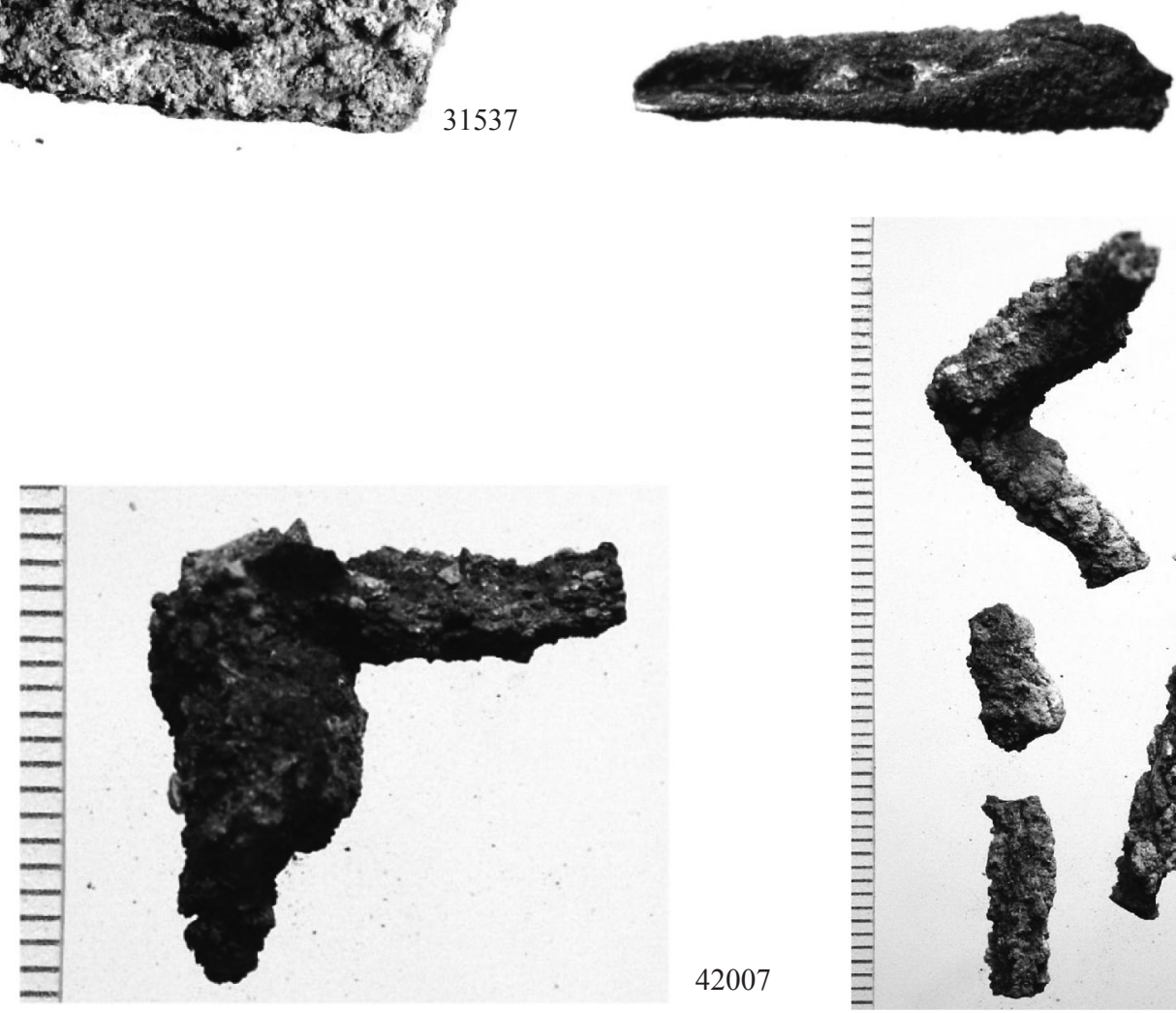

42007

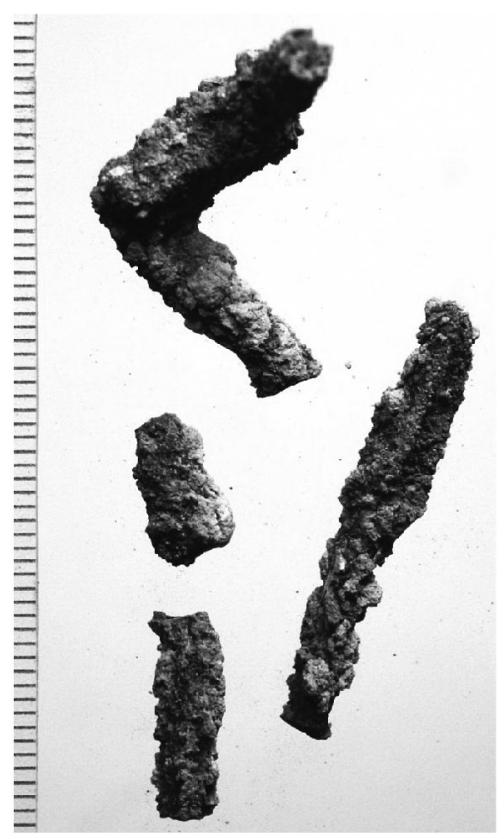

42010

Figura 9: Fíbulas de doble resorte de Fonteta I y II. 

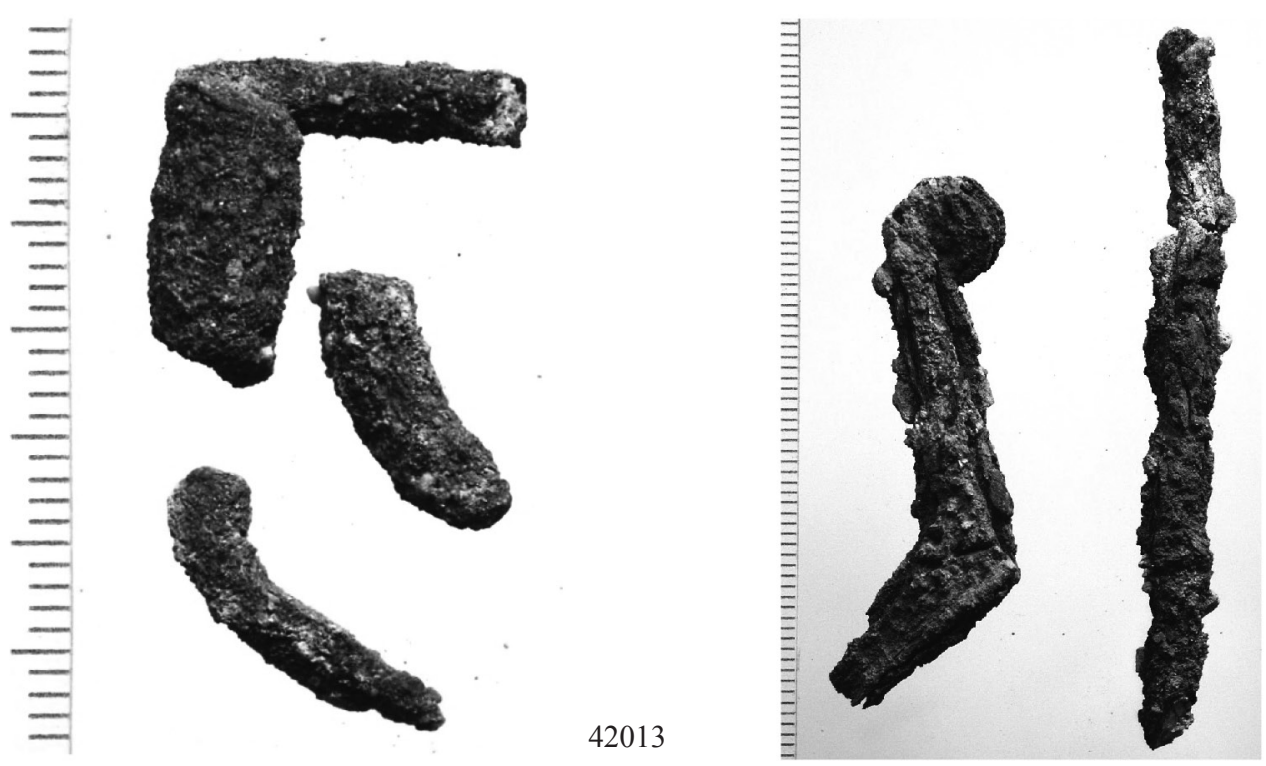

42020

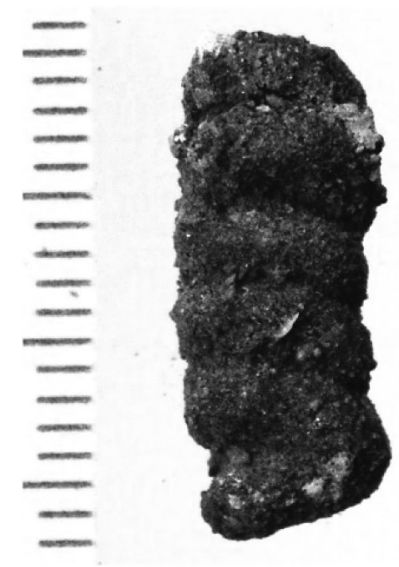

42023

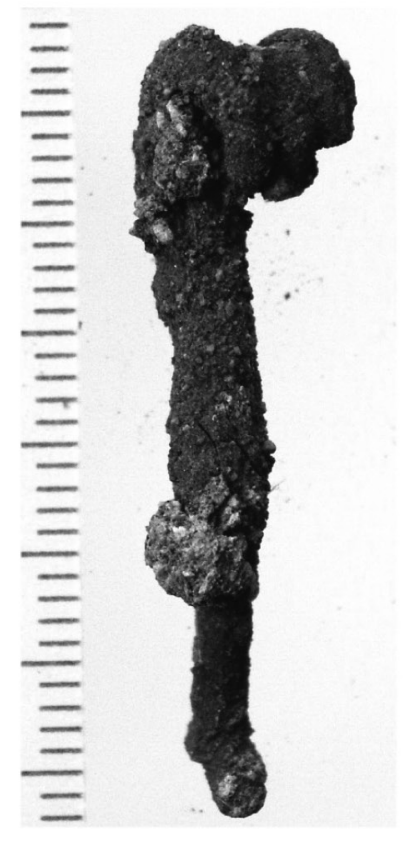

42036
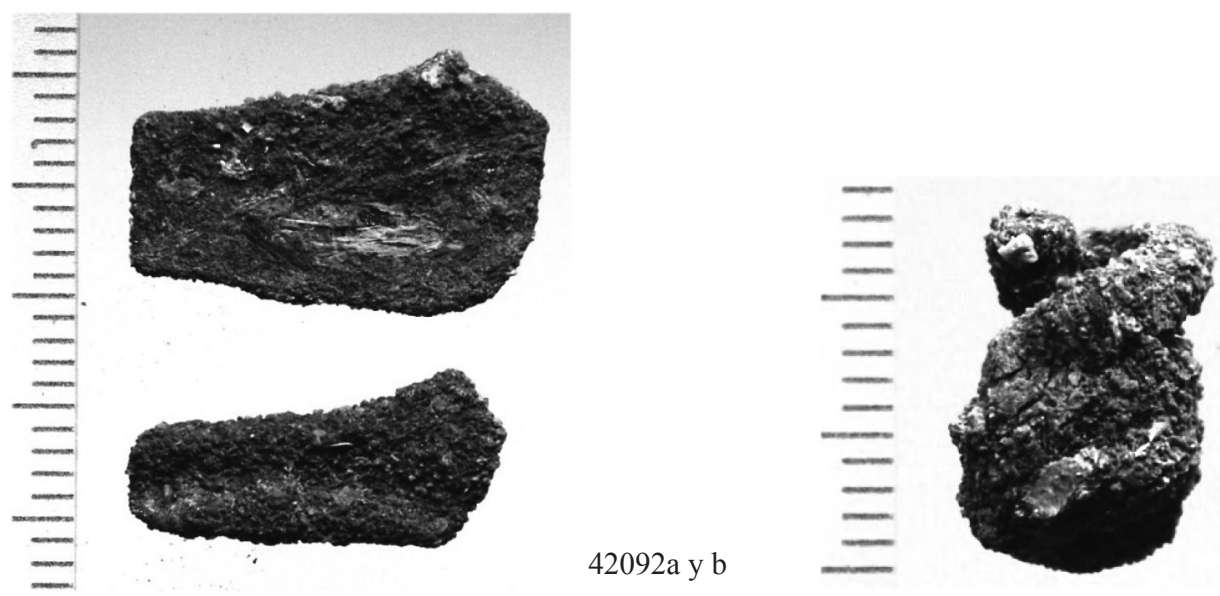

Figura 10: Elementos de fíbulas de doble resorte de Fonteta II. 

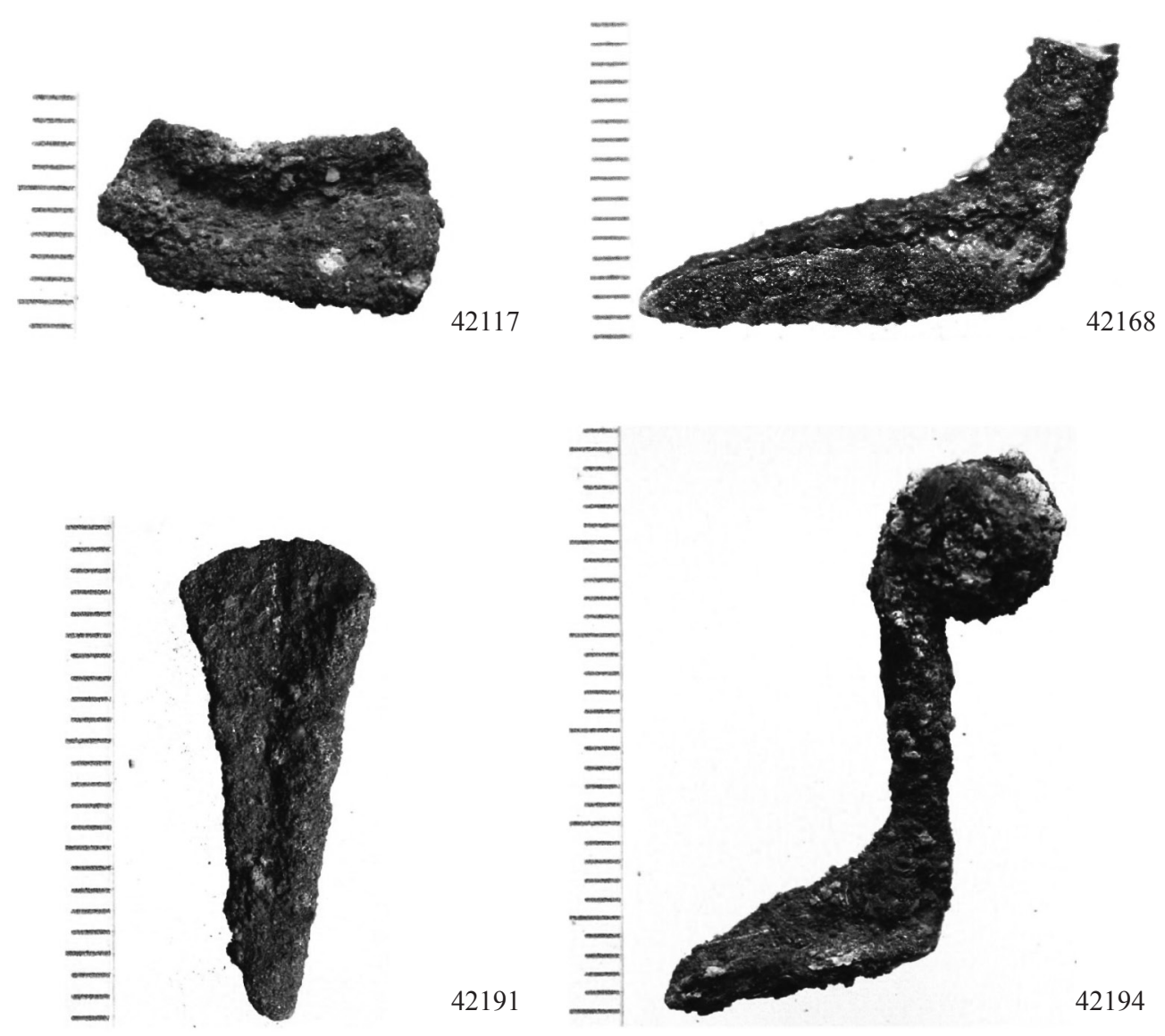

42194

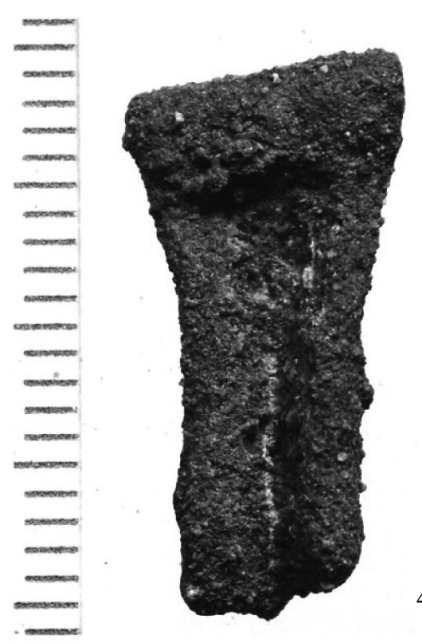

42204

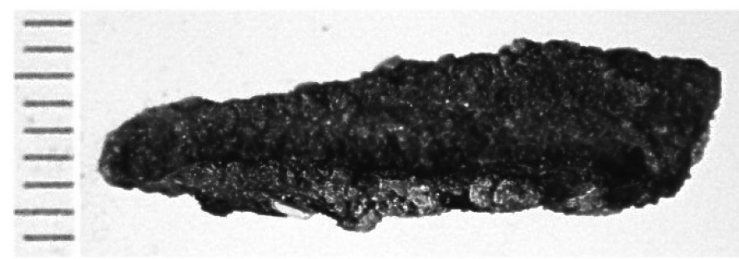

Figura 11: Fragmentos de fíbulas de doble resorte de Fonteta II. 

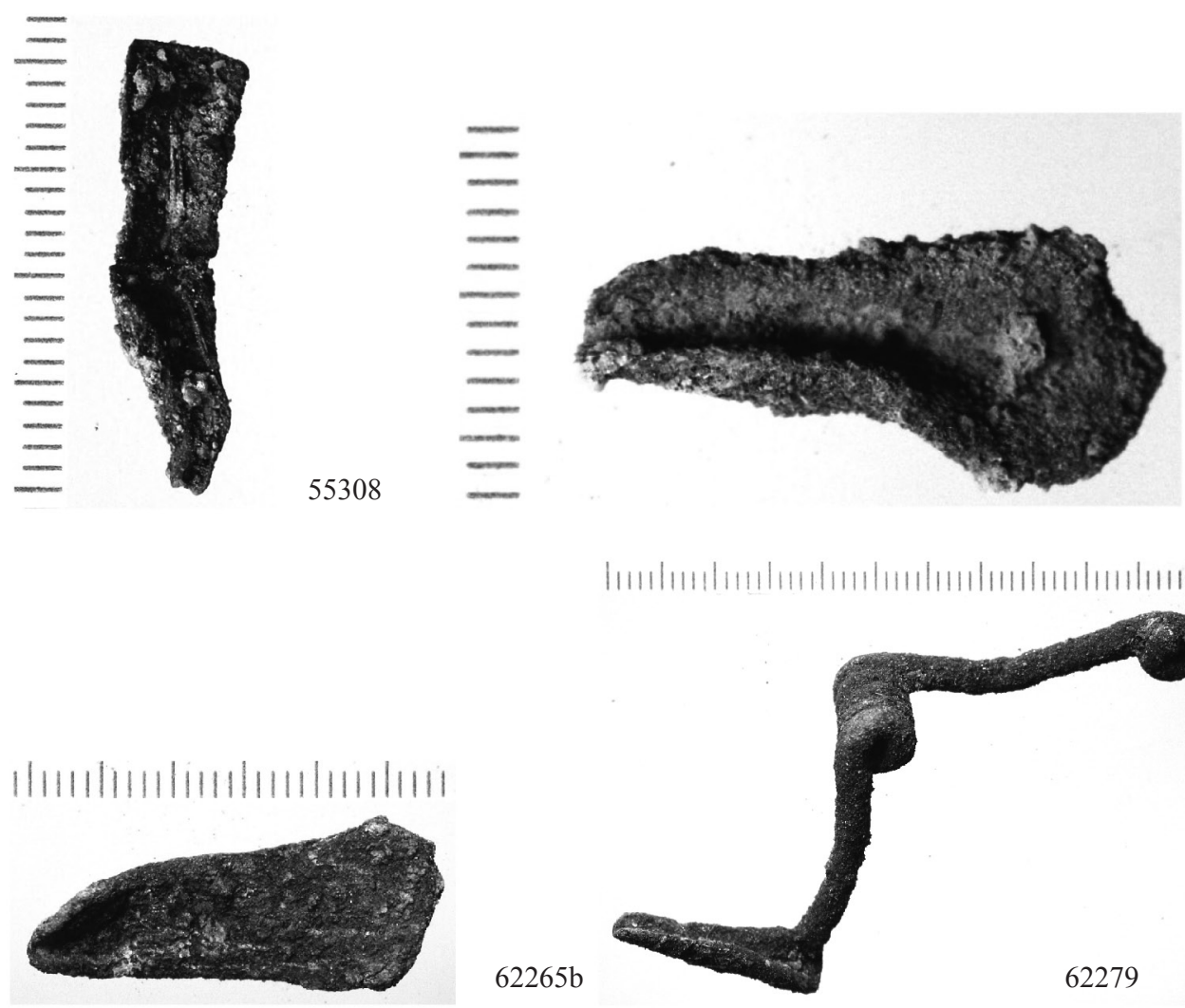

$62252 b$

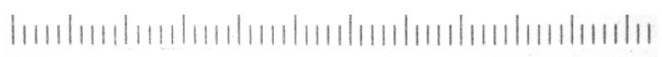

$62265 b$
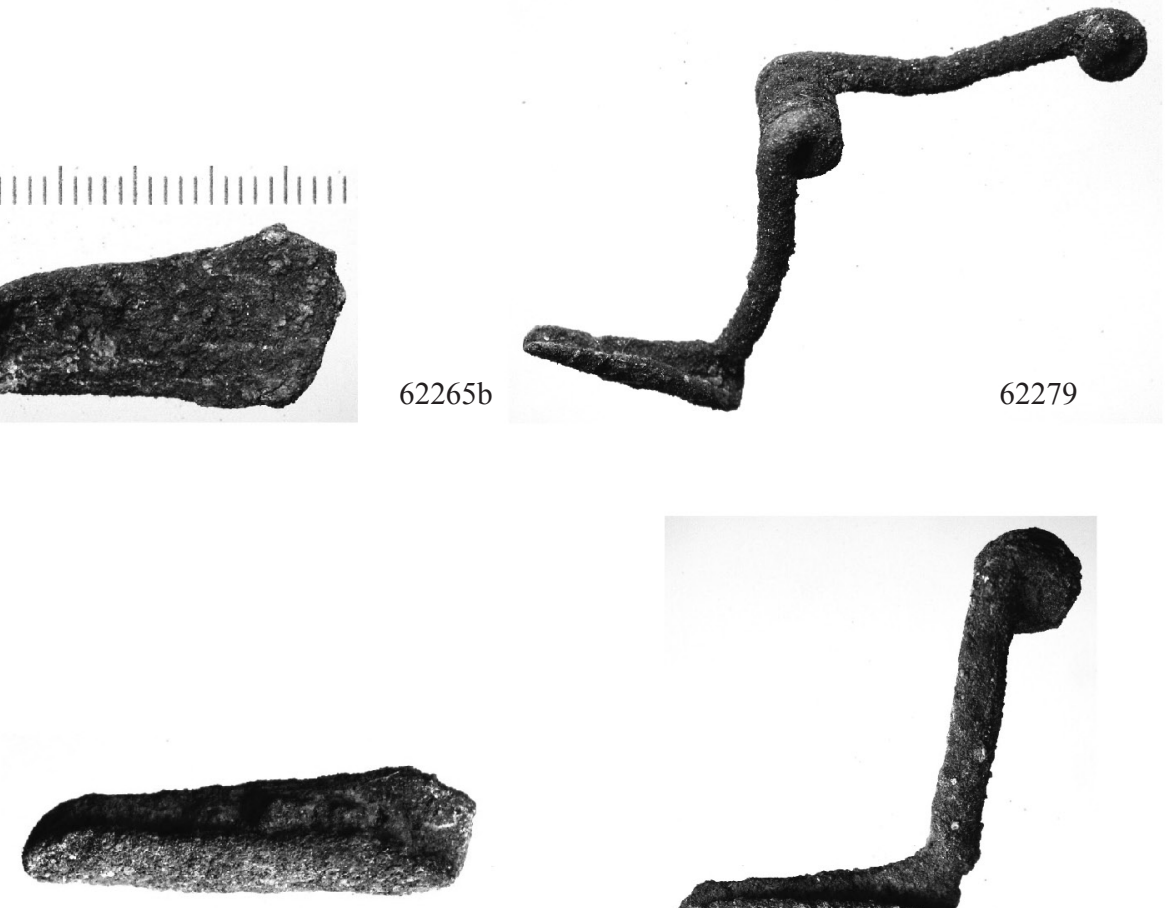

11\|\|\|\|\|\|\|\|\|\|\|\|\|\|$\| 62284$

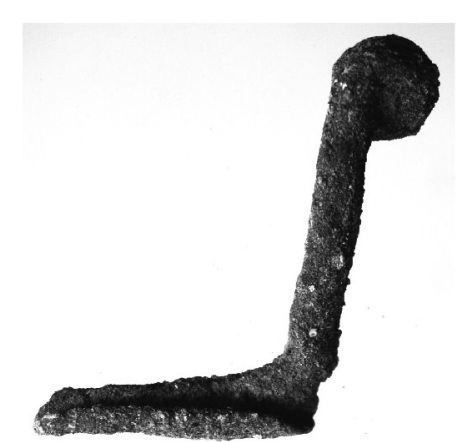

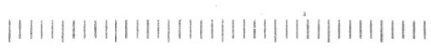

62295

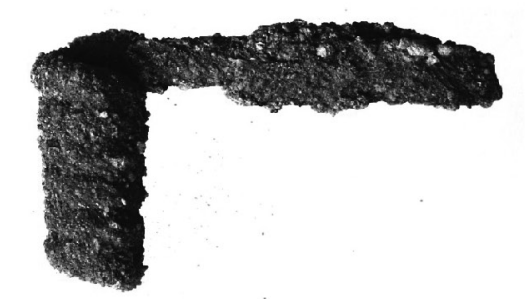

$1|1||||||||||||||||||||||||||||| \mid \quad 62325$

Figura 12: Fragmentos de fíbulas de doble resorte de Fonteta II. 
FÍBULAS Y ELEMENTOS FRAGMENTARIOS CORRESPONDIENTES A FASES POSTERIORES (Figs. 13-16)

25078. Mortaja plana. Bronce. Dimensiones: 11 x 9 mm. PE: 5A-B9. Fase III (670-635 aC).
31560. Mortaja. Bronce. Dimensiones: 29,3 x 9,3. PE: $8 \mathrm{BC}-\mathrm{A} 4 \mathrm{~b}$. Fase IV (635-625 aC).

5005. Mortaja. Bronce. Longitud: 33,6 mm. PE: 25A1. Fase VI (580-560 aC).

13029. Pie con mortaja y arco de cinta con nervadura central. Bronce. Dimensiones: 73 x 23,8 mm. PE: 8BC-A3b. Fase VI.

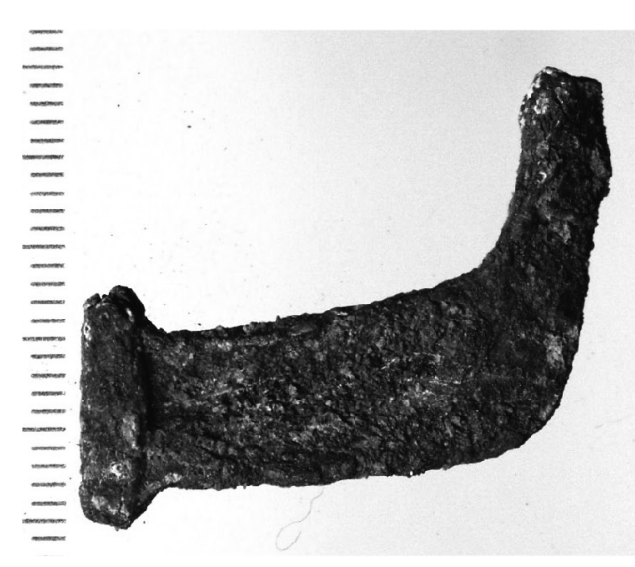

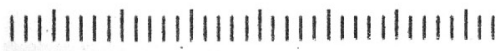

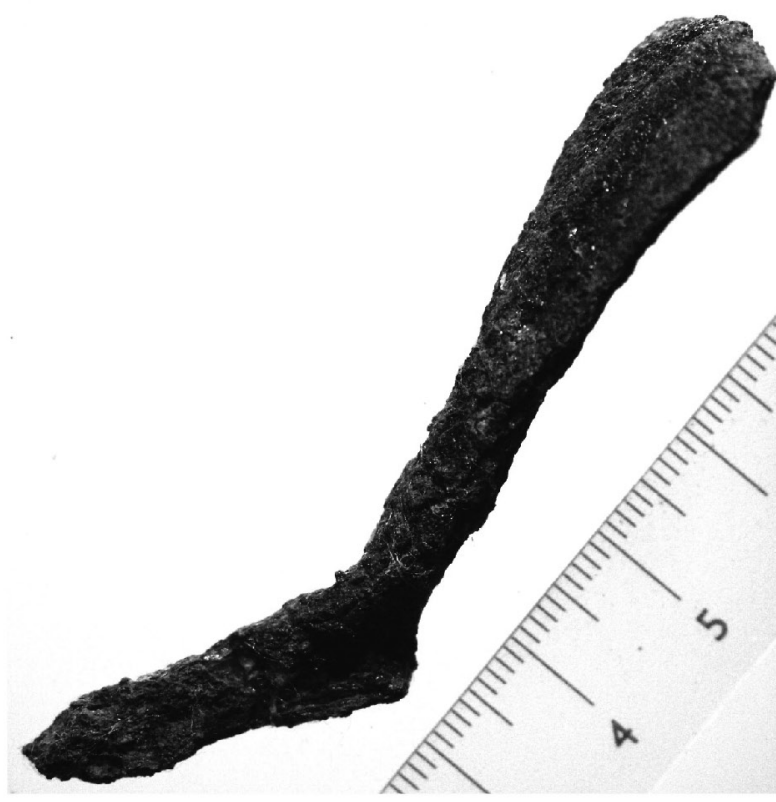

13029

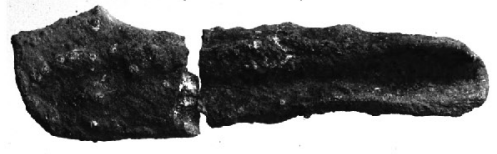

5005

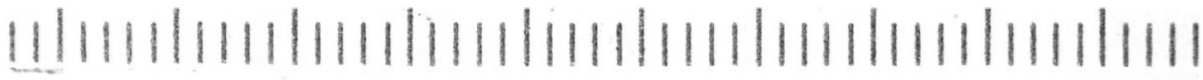

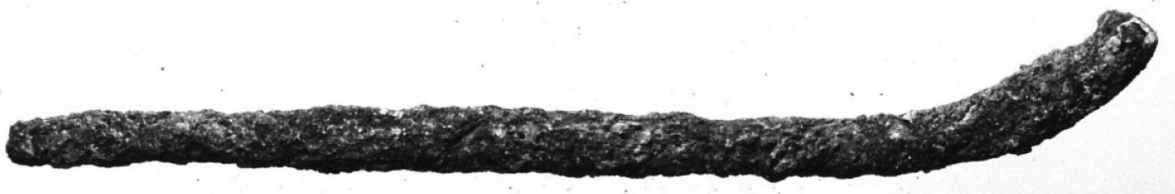

13106

Figura 13: Fragmentos de fíbulas de doble resorte y resorte bilateral de Fonteta III, IV y VI. 

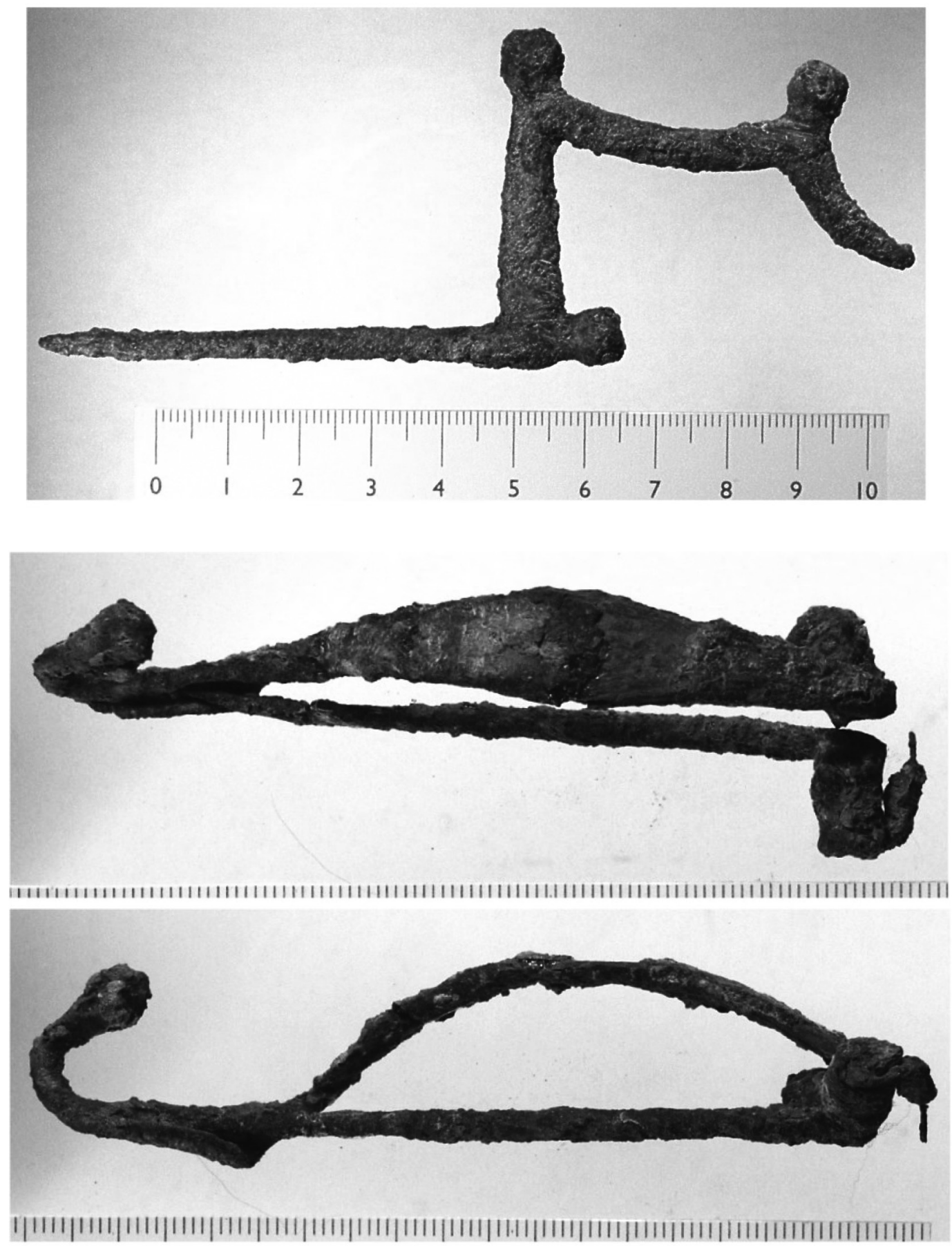

Figura 14: Fíbulas de aguja pivotante y de resorte bilateral de Fonteta VI.

13106. Aguja de fíbula. Bronce. Longitud: $49,4 \mathrm{~mm}$. Sección filamento: $3 \mathrm{~mm}$. PE: 8C-A3b. Fase VI.

15010. Fíbula con aguja pivotante. Arco con doble codo rematado por dos botones globulares. La aguja está dispuesta actualmente en posición opuesta a la mortaja. Bronce. Dimensiones: 80 x 40,7 mm. PE: 8BC-A3b. Fase VI.

15011. Fíbula de tipo Acebuchal-Alcores. Resorte bilateral, arco de cinta losángica y mortaja terminada con apéndice retraído rematado con botón. Bronce. Longitud: 90,8 mm. PE: 8C-A3b. Fase VI.

15012. Pie con mortaja de fíbula de doble resorte. Bronce. Dimensiones: 20 x 14,8 mm. PE: 7B-A3. Fase VI.

15031. Fíbula de doble resorte de seis espiras con travesaño terminal en la mortaja rematado por botones. Bronce. Longitud: 70,2 mm. PE: 8BC-A3b. Fase VI. 

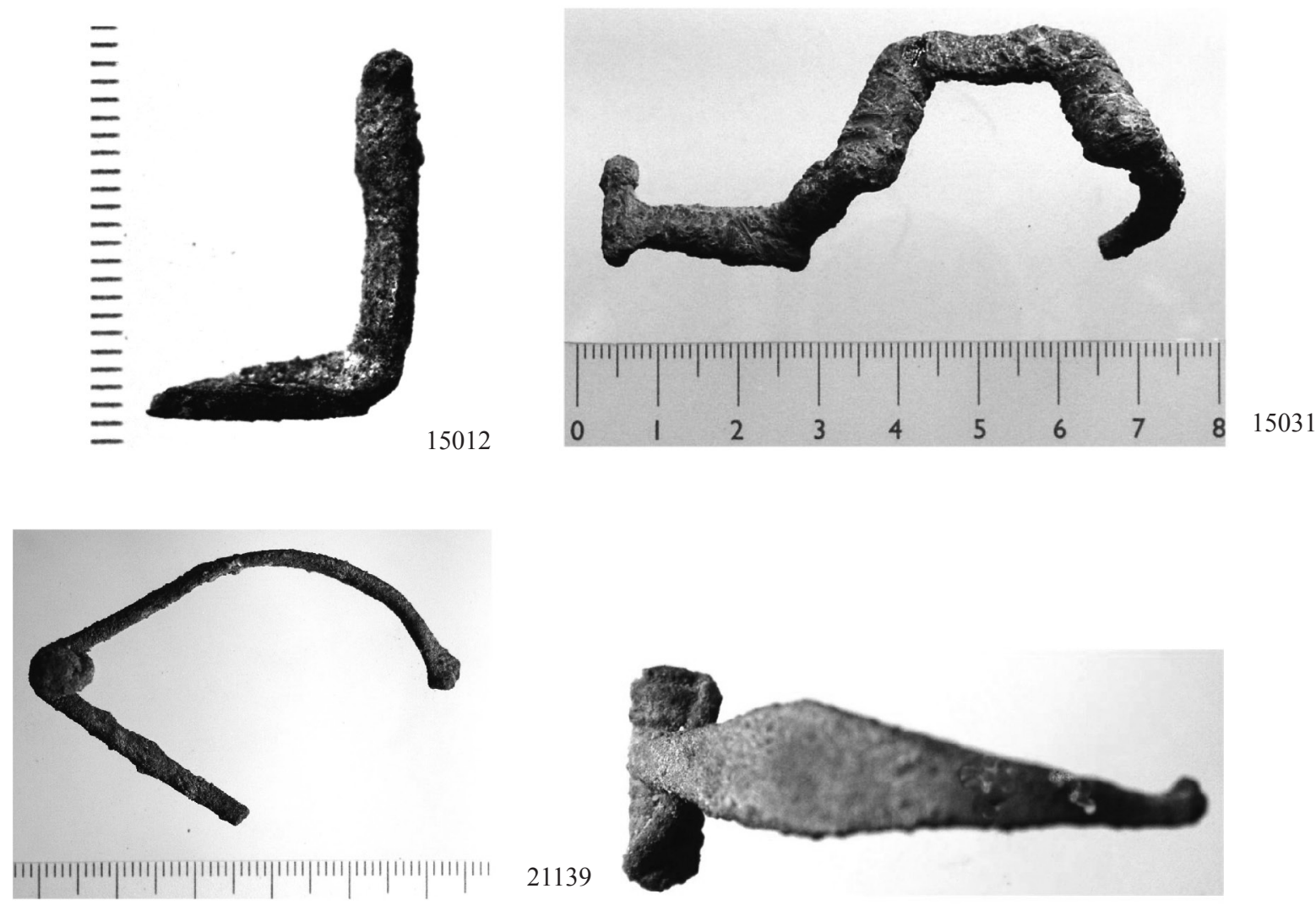

21139
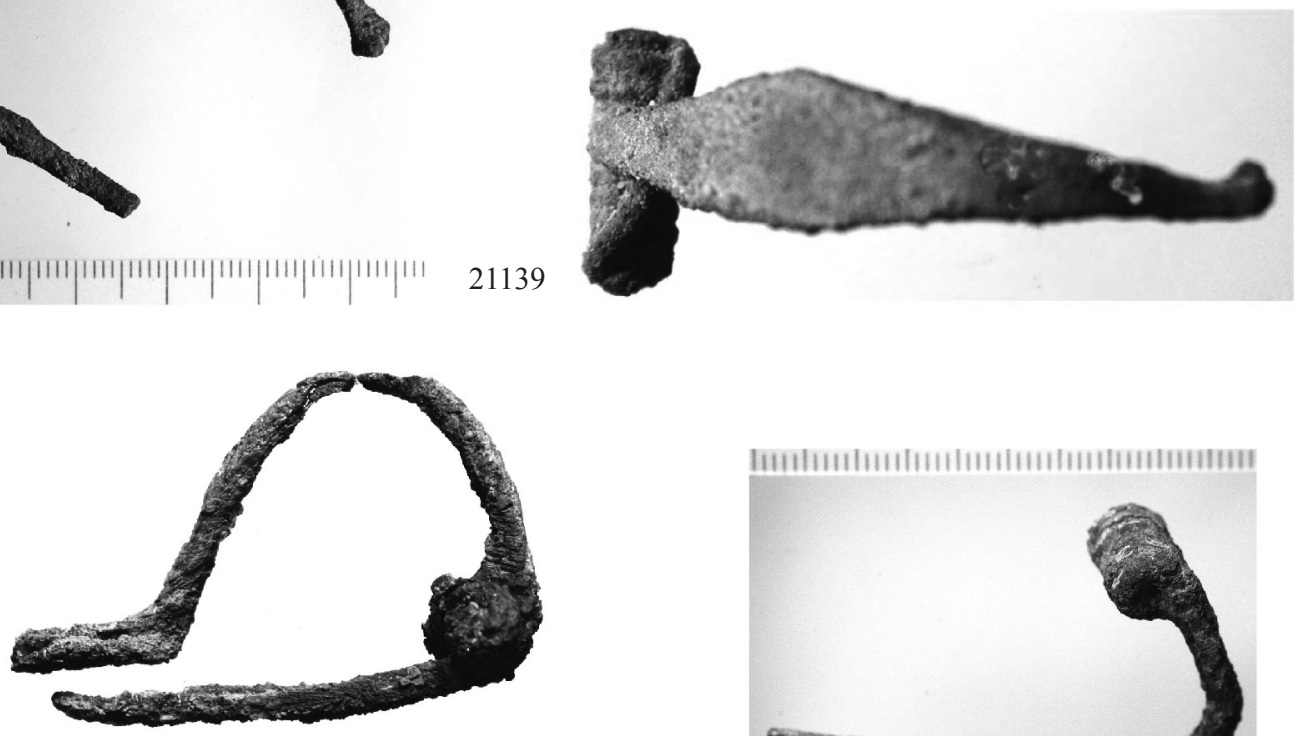

||I|||||||||||||||||||||||||||||||||||||||||||||| 25076
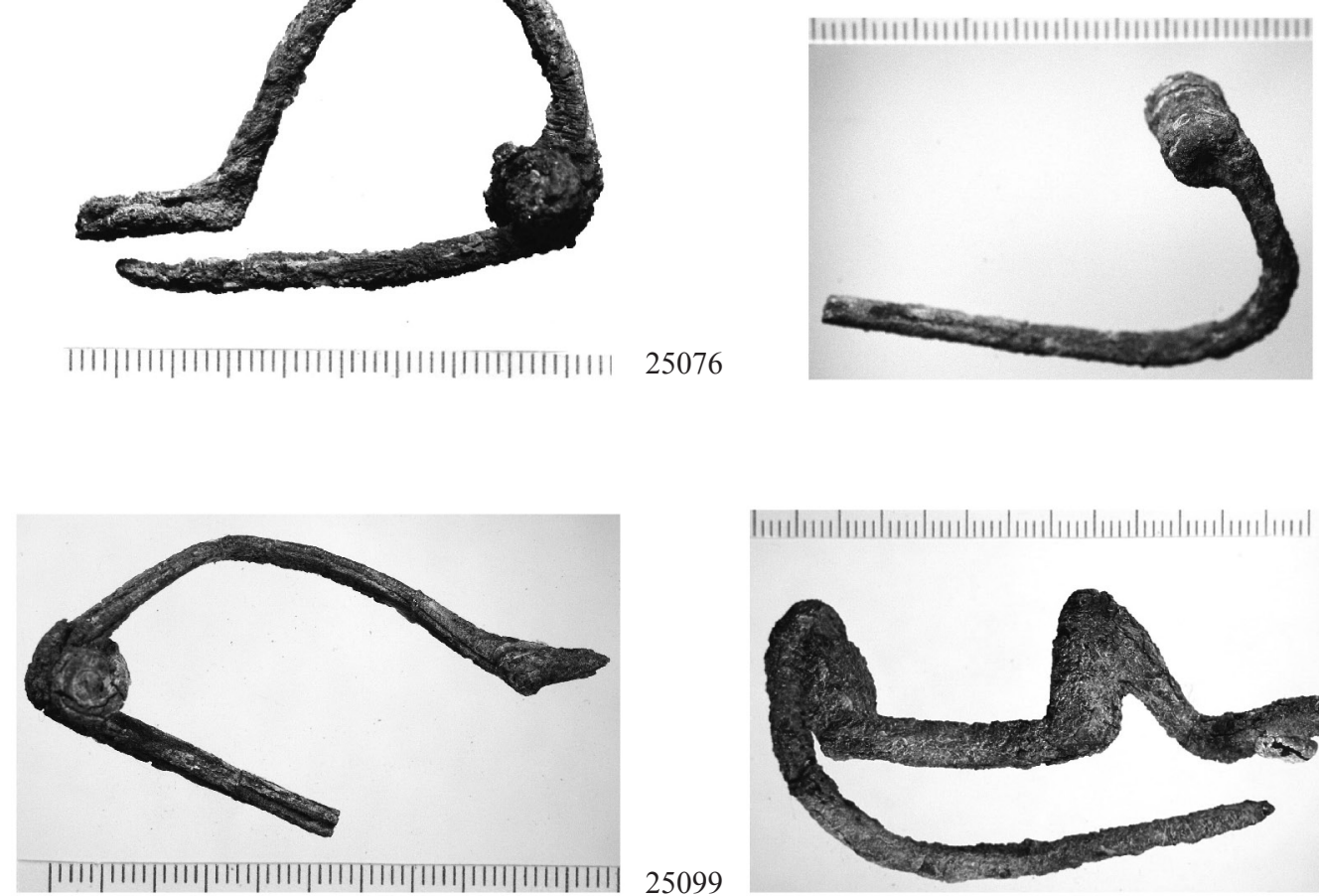

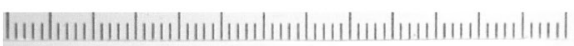

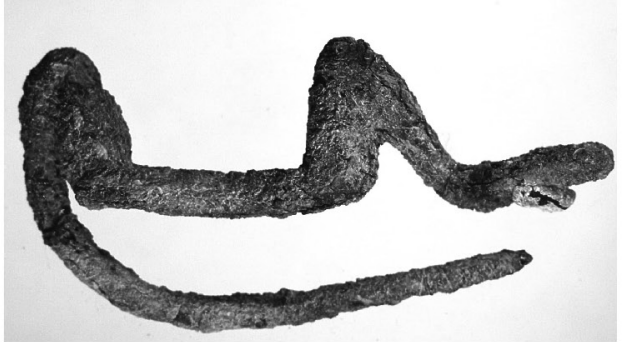

25100

Figura 15: Fíbulas de doble resorte y resorte bilateral de Fonteta VI. 


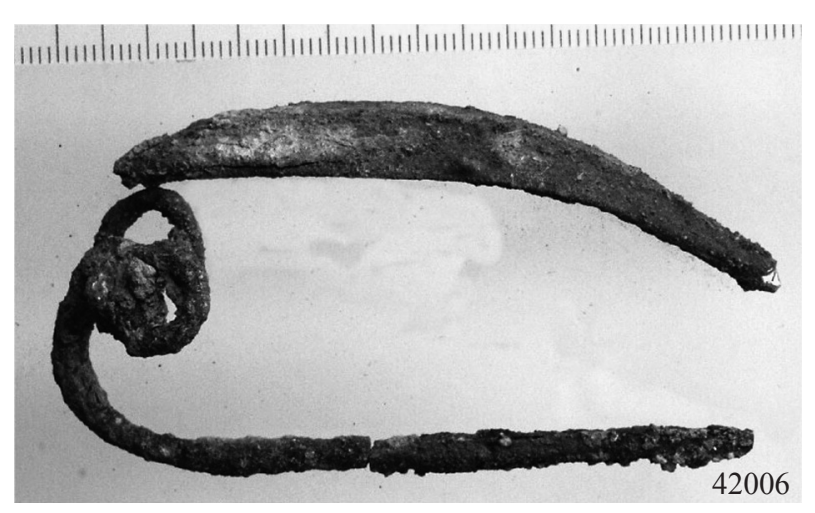

Figura 16: Fíbula de resorte bilateral y arco de cinta (tipo Acebuchal) de Fonteta VI.

21139. Fíbula de tipo Acebuchal-Alcores. Resorte bilateral con arco de cinta losángica. Bronce. Longitud: $56 \mathrm{~mm}$. PE: 8-A3. Fase VI.

25076. Fíbula con arco de cinta estrecha con resorte bilateral. Bronce. Longitud: $49 \mathrm{~mm}$. PE: 5N-A3. Fase VI.

25099. Fíbula con arco de cinta estrecha con resorte bilateral. Bronce. Longitud: 52,7 mm. PE: 8B-A3. Fase VI.

25100. Fíbula de doble resorte de seis espiras y filamento circular. Bronce. Longitud: 68,5 mm. PE: 8BC-A3. Fase VI.

42006. Fíbula de tipo Acebuchal incompleta. Resorte bilateral con aguja y arco de cinta con nervadura central. Bronce. Longitud: 77,7 mm. PE: 54S-A3b. Fase VI.

62328. Resorte con 5 espiras y aguja de fíbula de doble resorte. Bronce. Longitud: 46,8 mm. Filamento de 3,2 $\mathrm{mm}$ de sección. PE: 65-A2c. Fase VII $(560 / 550 \mathrm{aC})$.

\section{PENDIENTES SEMILUNARES}

En el mundo fenicio, los ejemplares realizados en oro son muy conocidos en la orfebrería fenicia, en ocasiones con la cruz egipcia soldada debajo del engrosamiento semilunar, como vemos en Cartago (Pisano, 1988, 370 y 371) o en Palermo (Spanò, 1995, láms. 2 y 3); portando un cestillo con pirámide de glóbulos (Harden, 1967, fig. 78) o con una esfera o granada, como el ejemplar de la Tumba 1 de Laurita (Pellicer, 2007, fig. 14,f). También aparecen en plata, como los ejemplares hallados en la cremación núm. 4 de San Giorgio di Portoscuso (Bernardini, 1997, 57). Su elaboración en bronce, como los que aquí presentamos, fue muy frecuente, y aparecen, entre otros, en contextos funerarios, como en la necrópolis de Akziv (Mazar, 2001, figs. 24, 57 y 66; 2004, fig. 24).

La mayor parte de los ejemplares de Fonteta han perdido la parte superior, la más débil, siendo identificados precisamente por el engrosamiento semilunar de la base. Sólo un ejemplar procede de Fonteta VI, perteneciendo el grueso a los depósitos metalúrgicos de Fonteta I y II.

PENDIENTES PROCEDENTES DE LOS DEPÓSITOS METALÚRGICOS (fig. 17)

42081. Fragmento de la parte inferior. Bronce. Dimensiones: 14,1 x 4,9 (sección) mm. PE: 54SW-B5f. Fase I (760-720 aC).

55304. Mitad inferior. Bronce. Dimensiones: $12,2 \mathrm{x}$ 14,5 (abertura) mm. PE: 1W-B4. Fase I.

35645. Mitad inferior. Bronce. Dimensiones: $9,2 \times$ 12,6 (abertura) mm. PE: 54N-B10. Fase II (720$670 \mathrm{aC})$

42016. Pendiente completo. Bronce. Dimensiones: 15,6 x 12 mm. PE: 54S-B1. Fase II.

42027. Mitad inferior. Bronce. Dimensiones: 18,6 x 4,6 (sección) mm. PE: 54-B3b. Fase II.

42047. Mitad inferior. Bronce. Dimensiones: 15 x 2,8 (sección) mm. PE: 54-B3c. Fase II.

42084. Pendiente incompleto. Bronce. Dimensiones: 18 x 3,7 (sección). PE: 54N-B8. Fase II.

45002. Pendiente incompleto. Bronce. Dimensiones: 21,7 x 13,7 mm. PE: 54N-B3e1. Fase II.

45040. Mitad inferior. Bronce. Dimensiones: 12,1 x 3,9 (sección) mm. PE: 54N-B1/B3d. Fase II.

55281. Parte inferior. Bronce. Dimensiones: 12,9 x 3,8 (sección) mm. PE: 1W-B1. Fase II.

55286. Pendiente casi completo. Bronce. Dimensiones: 15,3 x 10,4 mm. PE: 1W-B1. Fase II.

55290. Pendiente completo. Bronce. Dimensiones: 13,7 x 15,1 mm. PE: 1W-B1b. Fase II.

55291. Pendiente completo cerrado. Bronce. Dimensiones: $9,3 \times 11 \mathrm{~mm}$. PE: $1 \mathrm{~W}-\mathrm{B} 1 \mathrm{~b}$. Fase II.

55314. Pendiente completo. Bronce. Dimensiones: 19,6 x 13,2 (abertura) x 2,6 (sección) mm. PE: 1WC-B2ab. Fase II.

62271b. Mitad inferior. Bronce. Dimensiones: 16,5 x 11,4 x 4,1 mm. PE: 1N-B2a. Fase II.

62280. Mitad inferior. Bronce. Dimensiones: 10,9 x 9,5 mm. PE: 1-B1. Fase II.

\section{PENDIENTE PROCEDENTE DE OTRA FASE}

13030. Mitad inferior. Bronce. Dimensiones: 15 x 4 mm. PE: 8B-A3a. Fase VI.

\section{CUCHILLOS DE HIERRO}

Estas piezas pasan por ser uno de los primeros objetos del nuevo metal que inaugura el Hierro Antiguo en el occidente europeo. Como tales, e introducidos por los fenicios (Mansel, 2000, fig. 6; Mancebo Dávalos, 2000, 1829), debieron constituir objetos de prestigio entre los autóctonos ya que su reiterada presencia en tumbas importantes de las necrópolis tartéssicas, 

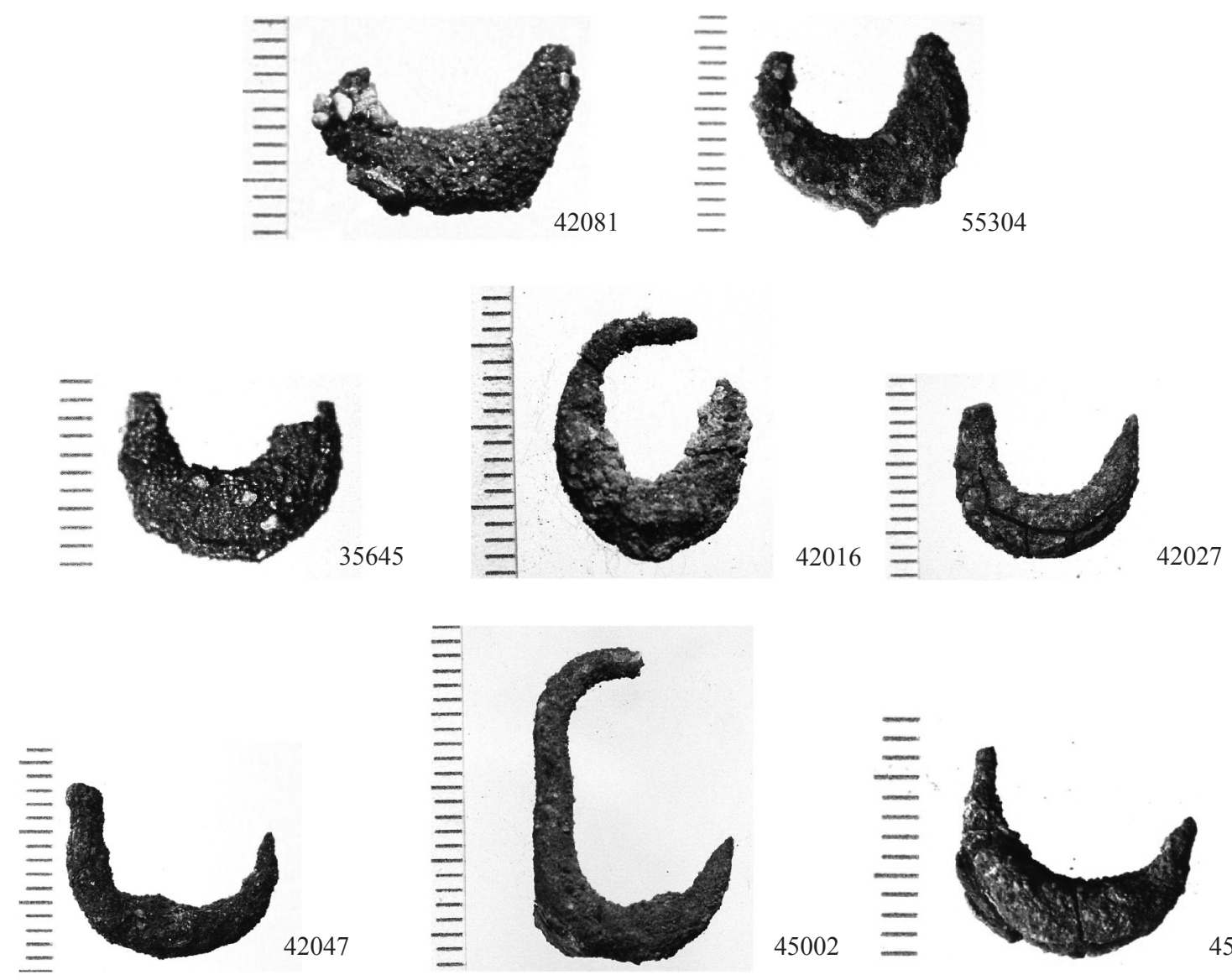

45040
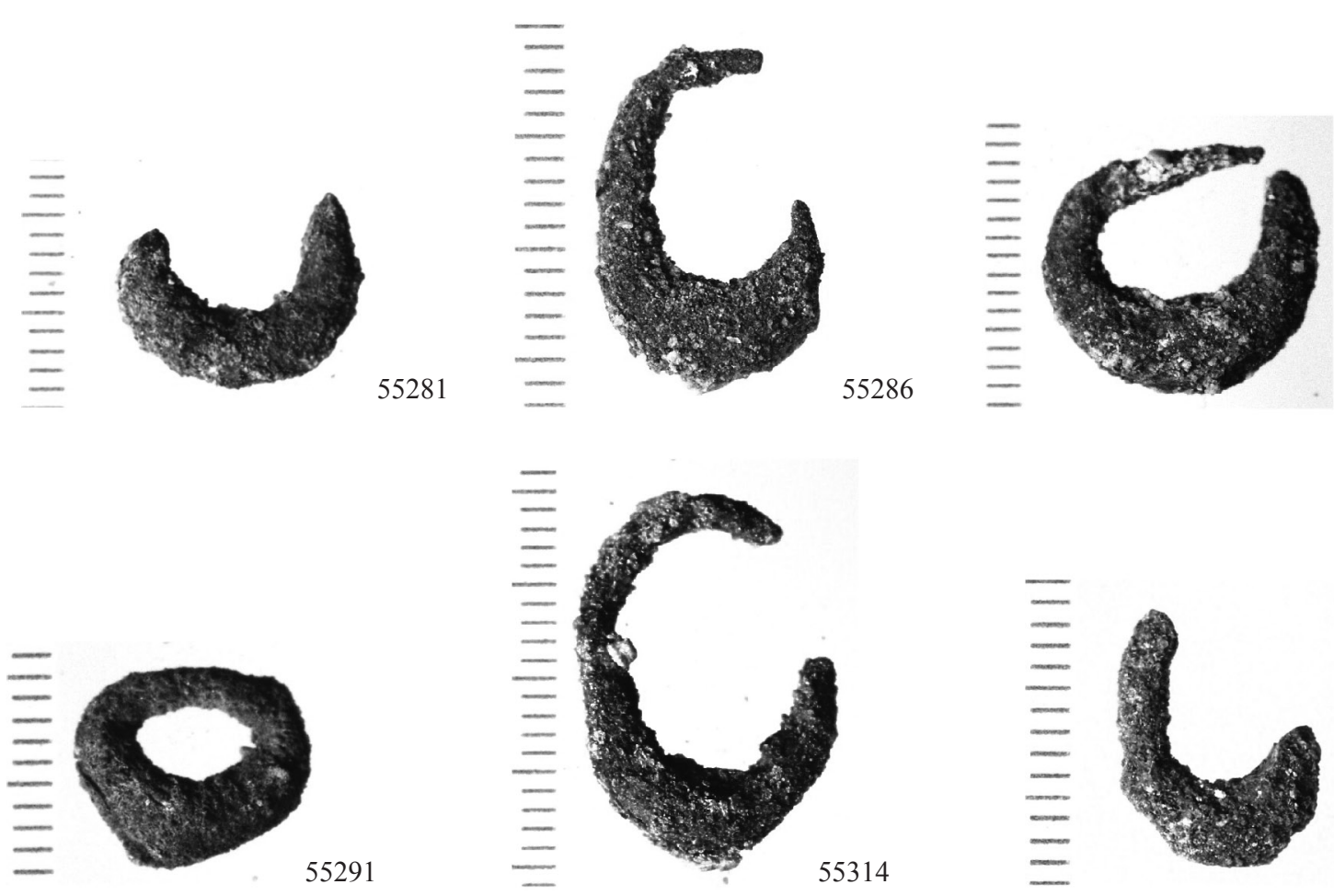

62280

Figura 17: Pendientes semilunares de los depósitos metalúrgicos de Fonteta I y II. 
en ocasiones acompañando a fíbulas de doble resorte (Setefilla: Aubet, 1975, figs. 8, 19, 23, 53 y 54; La Joya: Garrido, 1979, figs. 24 y 31; Medellín: Almagro Gorbea, 1977; Lorrio Alvarado, 2008), o su inclusión en el tesorillo de Peña Negra (González Prats, 1976), apuntan en ese sentido.

Los ejemplares hallados en Fonteta, tanto en los depósitos metalúrgicos arcaicos como en el resto de la secuencia, que recogemos, corresponden a cuchillos de hoja curvada o afalcatada y presentan por lo general una hoja de sección triangular. La longitud estaría en torno a los 120-134 mm, con anchuras que oscilan entre 14 y $23 \mathrm{~mm}$.

El hallazgo en estos depósitos metalúrgicos de fragmentos de mangos de hueso y marfil con perforaciones, y uno completo aún con los remaches adheridos al mango metálico (Fig. 24), nos indica el tipo de guarnición con que se cubría la pieza metálica para su manejo, en ocasiones reforzada en su unión por grapas de bronce. Numerosas huellas de uso de un elemento metálico cortante sobre el interior de platos de engobe rojo y grises, es decir sobre los platos de mesa, habrían sido producidas por estos cuchillos de hierro.

No es improcedente pensar que fueran elaborados in situ, puesto que la actividad metalúrgica que observamos en La Fonteta, y que afecta al trabajo siderúrgico, debió de proveer a sus habitantes de los elementos metálicos habituales en su vida cotidiana.

PIEZAS HALLADAS EN LOS DEPÓSITOS METALÚRGICOS (Figs. 18-19)

42075. Fragmento de hoja. Hierro. Dimensiones: 43,3 x 16,7 mm. PE: 54SW-B5f. Fase I.

55272. Fragmento de mango de cuchillo con remaches y refuerzo de grapa de bronce. Hierro. Dimensiones: 55,6 x 20 mm. 54N-B13. Fase I.

42019. Fragmento de hoja curvada. Hierro. Dimensiones: 76,6 x 18 mm. PE: 54N-B4b. Fase II. En el filo interior se halla una cuenta de collar discoidal de fayenza atrapada por la concreción férrica.

42054. Fragmento de hoja. Hierro. Dimensiones: 26 x 17 mm. PE: 54S-B4. Fase II.

42094. Fragmento de hoja. Hierro. Dimensiones: 43,9 x 21,2 mm. PE: 54N-B6. Fase II.

42120. Fragmento de hoja. Hierro. Dimensiones: 33,9 x 14,5 mm. PE: 54N-B8/9. Fase II.

42126. Extremo apuntado. Hierro. Dimensiones: 40,1 x 13,4 mm. PE: 54N-B3ef. Fase II.

42226. Fragmento de hoja. Hierro. Dimensiones: 31 x 12,2 mm. PE: 54N-B8. Fase II.

42285. Fragmento de hoja. Hierro. Dimensiones: 40,8 x 18,3 mm. PE: 54N-B8. Fase II.

55259. Fragmento de hoja. Hierro. Dimensiones: 41,9 x 21,4 mm. PE: 1W-B1. Fase II.

55292. Fragmento de hoja. Hierro. Dimensiones: 25,2 x 14,2 mm. PE: 1WC-B3. Fase II.
62241. Fragmento de hoja. Hierro. Dimensiones: 27,5 x 13,4 mm. PE: 1N-B2a. Fase II.

62251b. Fragmento de hoja. Hierro. Dimensiones: 49 x 18,6 mm. PE: 1N-B2a. Fase II.

62259. Fragmento apuntado de hoja. Hierro. Dimensiones: 35,2 x 13,3 mm. PE: 1N-B2a. Fase II.

62275b. Fragmento de hoja. Hierro. Dimensiones: 32,5 x 20 mm. PE: 14N-B10a. Fase II.

62278a. Fragmento de hoja. Hierro. Dimensiones: 19,6 x 20,6 mm. PE: 14E-B10b. Fase II.

PIEZAS PROCEDENTES DEL RESTO DE LA SECUENCIA (Figs. 20-24)

13060. Extremo apuntado. Hierro. Dimensiones: 32,9 x $11 \mathrm{~mm}$. PE: 14NW-B9a. Fase III.

13063. Hoja fragmentada. Hierro. Dimensiones: 80,3 x 12,5 mm. PE: 14NE-B9a. Fase III.

13064b. Fragmento de hoja. Hierro. Dimensiones: 49 x 10,6 mm. PE: 14NE-B9a. Fase III.

13071b. Fragmento de hoja. Hierro. Dimensiones: 22,6 x 15,5 mm. PE: 14NE-B9a. Fase III.

31518. Fragmento de hoja. Hierro. Dimensiones: 40,5 x 12,5 mm. PE: 5C-A4. Fase IV.

31519. Fragmento de hoja. Hierro. Dimensiones: 24,5 x $24 \mathrm{~mm}$. PE: 5C-A4. Fase IV.

10107. Cuchillo de hoja curvada de sección triangular. Hierro. Dimensiones: 117,6 x 14,8 mm. PE: 7BA3. Fase VI. Conserva dos agujeros claros para remaches y restos de las fibras leñosas del mango (madera).

13077. Hoja de cuchillo curvado de sección triangular. Hierro. Dimensiones: 106,4 x 15,4 mm. PE: 8BCA3b. Fase VI.

25092. Hoja curvada. Hierro. Dimensiones: 133,7 x $22 \mathrm{~mm}$. PE: 5N-A3. Fase VI.

31506. Fragmento de hoja con impronta orgánica. Hierro. Dimensiones: 42,3 x 15 mm. PE: 5B-A3b. Fase VI.

31544. Fragmento de hoja curvada y apuntada de sección triangular. Hierro. Dimensiones: 80,8 x 23,8 mm. PE: 5N-A4a. Fase VI.

55264. Fragmento de hoja. Hierro. Dimensiones: 27,8 x 7,8 mm. PE: 1E-A3b. Fase VI.

Estos son los cuatro elementos metálicos que hemos querido presentar aquí como avance de la producción metalúrgica de la colonia fenicia de La Fonteta, que viene a completar el material similar publicado por Mansel, procedente de la fase más arcaica del Morro de Mezquitilla, y en consonancia igualmente con una actividad metalúrgica Como hemos indicado anteriormente, en la monografía correspondiente se presentará en breve el numeroso conjunto de útiles y objetos suntuarios de toda la secuencia estratigráfica. Otros tipos metálicos pueden haber salido igualmente de los talleres de este emporio costero, cuya documentación de carácter arqueometalúrgico es de primera magnitud 


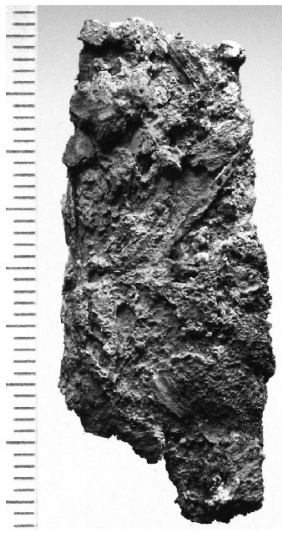

42075

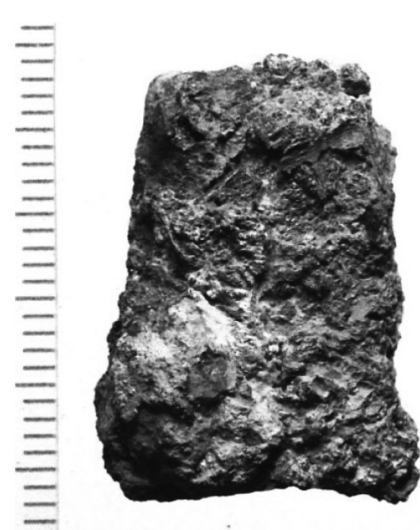

42054

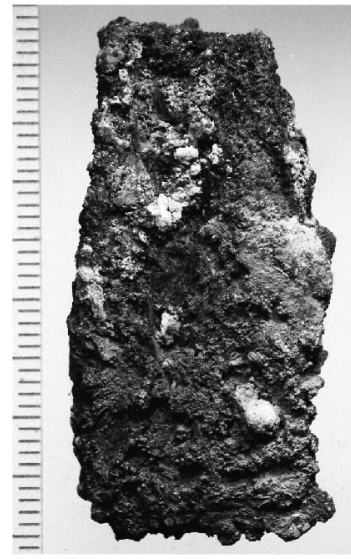

42094

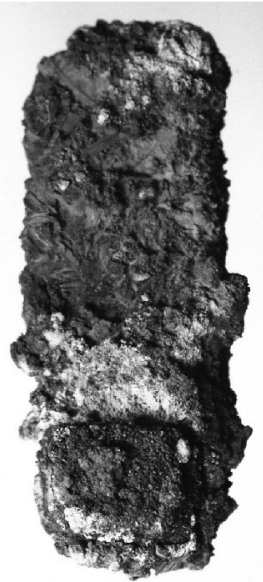

55272

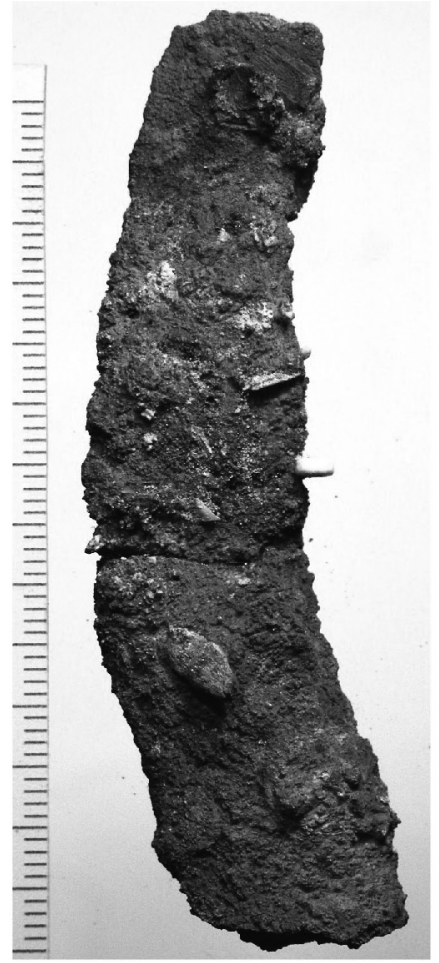

42019

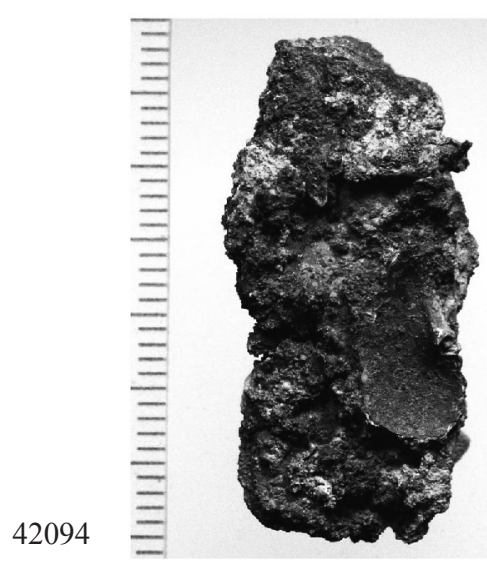

42120

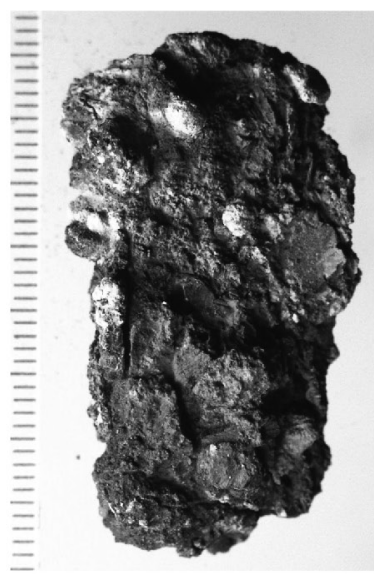

42285

Figura 18: Fragmentos de cuchillos de hierro de Fonteta I y II. 

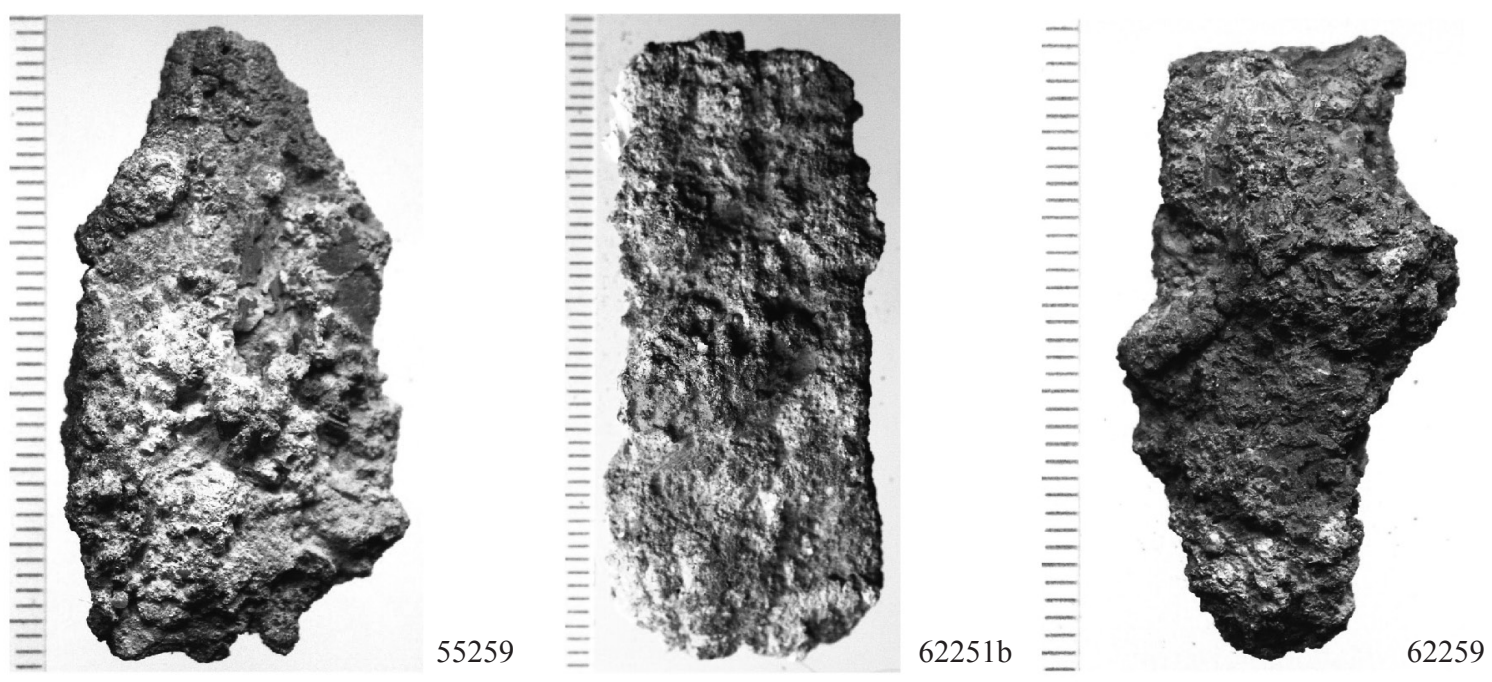

Figura 19: Fragmentos de hojas de cuchillos de Fonteta II.
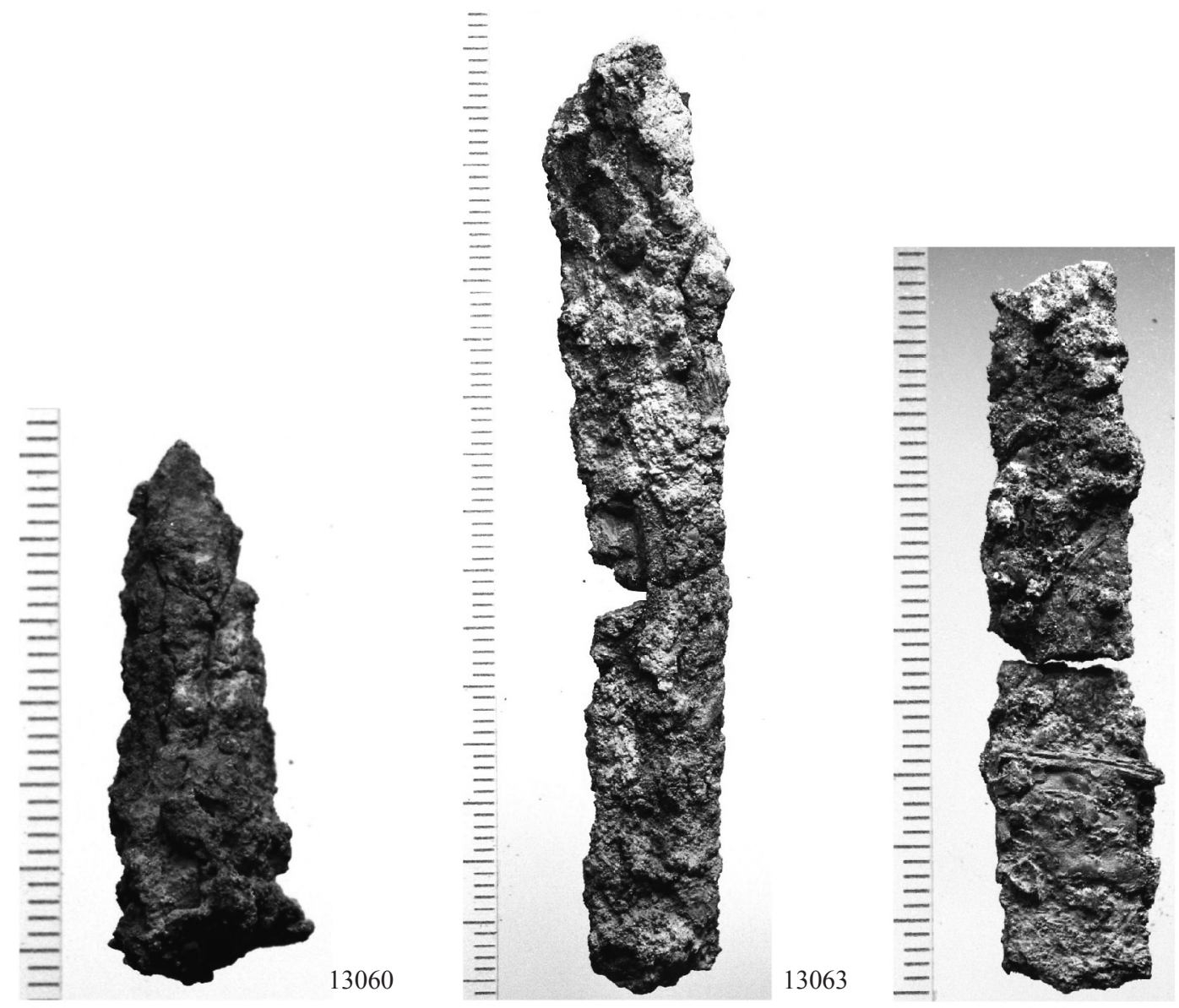

$13064 b$

Figura 20: Hojas de cuchillos de Fonteta III. 

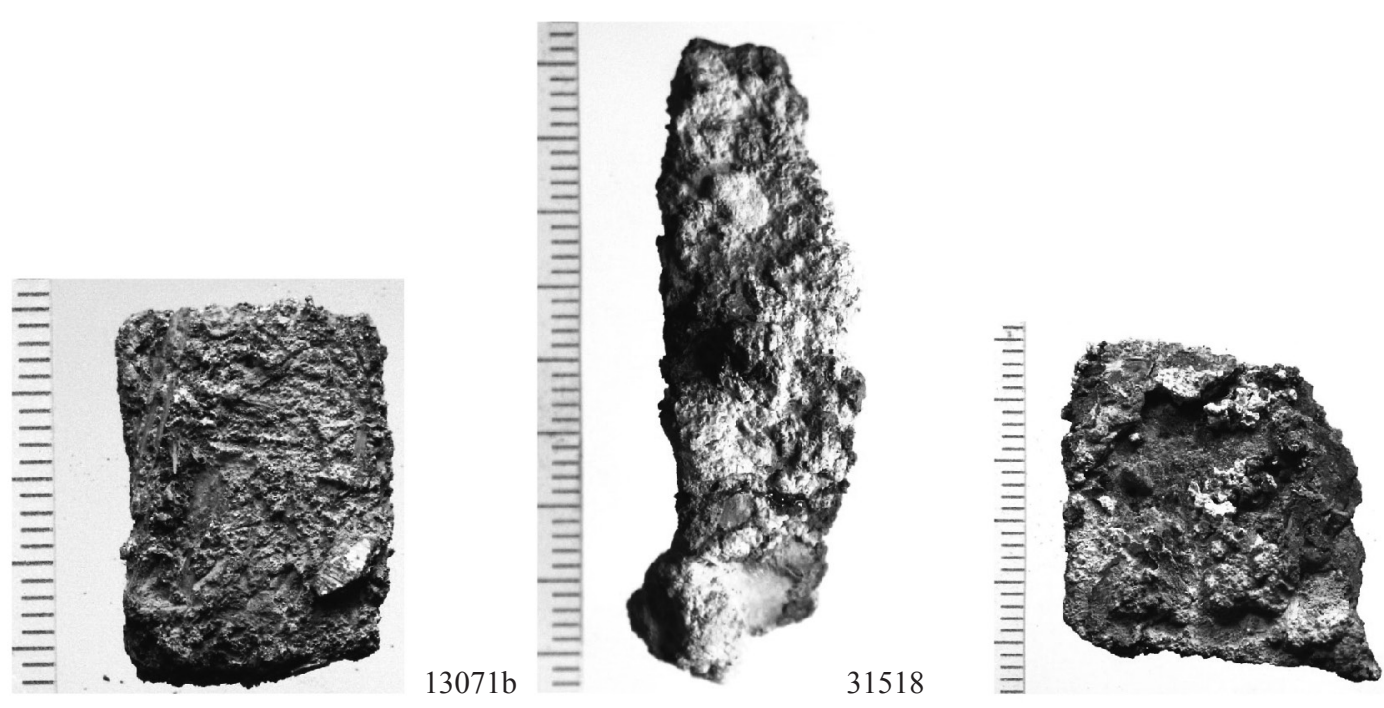

Figura 21: Fragmentos de hojas de cuchillo de Fonteta III y IV.
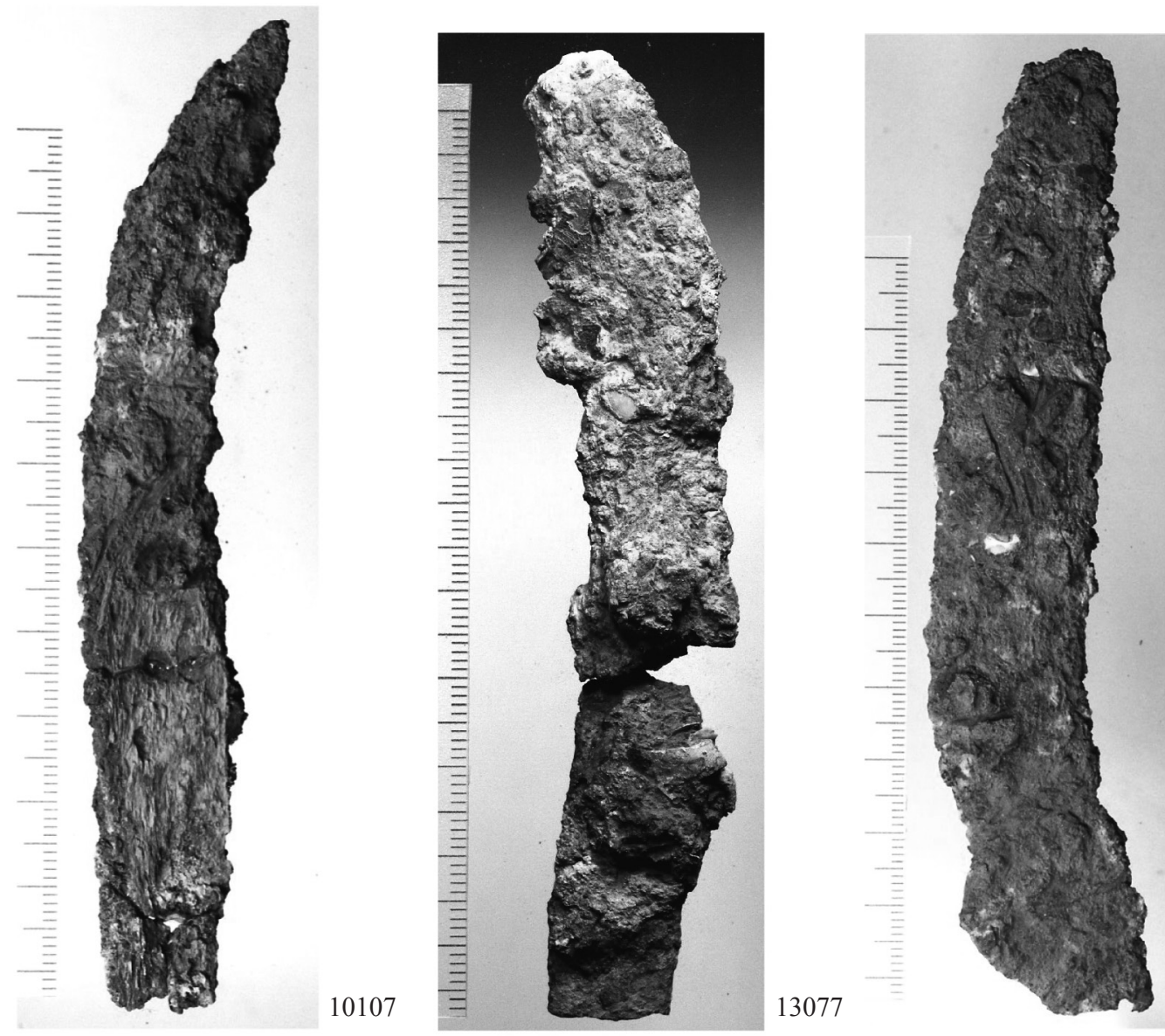

25092

Figura 22: Cuchillos de Fonteta VI. 

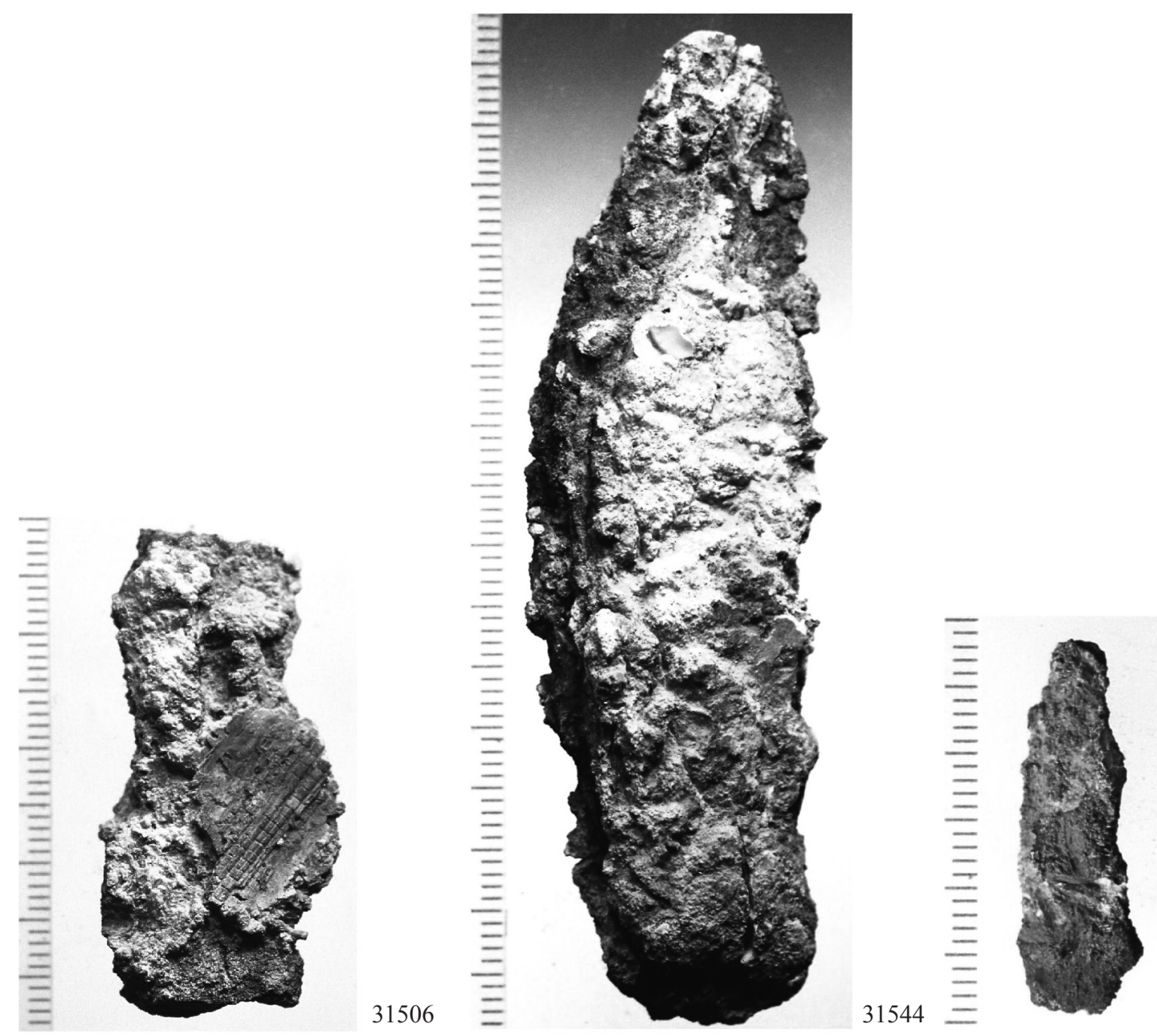

Figura 23: Hojas de cuchillos de Fonteta VI.
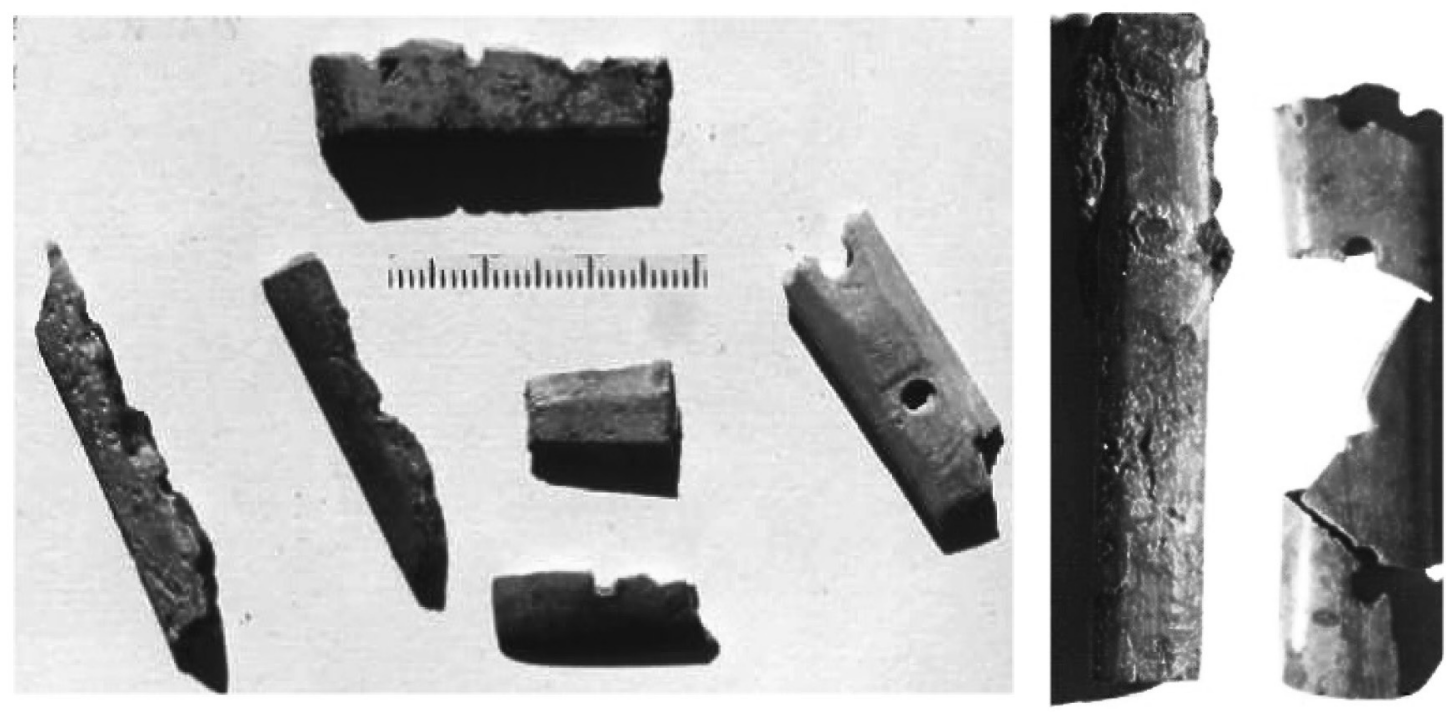

Figura 24: Mangos de hueso y marfil de cuchillos de hierro de Fonteta II. 
para el conocimiento de las actividades y producciones metalúrgicas de los centros fenicios occidentales.

\author{
Prof. Dr. Alfredo González Prats \\ Área de Prehistoria \\ Dpto. Prehistoria, Arqueología, $\mathrm{H}^{\mathrm{a}}$ Antigua, \\ Filología Griega y Filología Latina \\ Universidad de Alicante \\ 03080 Alicante \\ alfredo.gonzalez@ua.es
}

\section{BIBLIOGRAFÍA}

ALMAGRO GORBEA, M., 1977: El Bronce Final y el Periodo Orientalizante en Extremadura, Biblioteca Praehistorica Hispana, XIV, Madrid.

AUBET SEMMLER, M.E., 1975: La necrópolis de Setefilla en Lora del Río, Sevilla, PIP, II, Barcelona.

BERNARDINI, P., 1997: «La necropoli fenicia di San Giorgio di Portoscuso», en P. BERNARDINI, R. D'ORIANO y P. G. SPANU, Phoinikes BSHRDN. I Fenici in Sardegna, 55-57, Oristano.

GARRIDO ROIZ, J.P., 1970: Excavaciones en la necrópolis de La Joya, Huelva. ( $1^{a}$ y $2^{a}$ campañas), Excavaciones Arqueológicas en España, 71, Madrid.

GONZÁLEZ PRATS, A., 1981: «El tesorillo de tipo orientalizante de la Sierra de Crevillente, Alicante», Ampurias, 38-40 (1976-1978), 349-360.

GONZÁLEZ PRATS, A., 1983: Estudio arqueológico del poblamiento antiguo de la Sierra de Crevillente (Alicante), Anejo 1 de la revista Lucentum, Alicante.

GONZÁLEZ PRATS, A., 1999: El emporio fenicio de la desembocadura del río Segura (Guardamar del Segura, Alicante, España), Guía de la Exposición Monográfica con motivo del II Seminario Internacional sobre Temas Fenicios, Alicante.

GONZÁLEZ PRATS, A. y RUIZ SEGURA, E., 1999: «Una zona metalúrgica de la primera mitad del siglo VII en la ciudad fenicia de La Fonteta (Guardamar, Alicante)», XXIV Congreso Nacional de Arqueología (Cartagena, 1997), vol. 3, Cartagena, 355-357.

GONZÁLEZ PRATS, A. y RENZI, M., 2003: «El hombre y los metales», en J. A. ZAMORA (ed.), El hombre fenicio. Estudios y materiales, Roma, 147-159.

HARDEN, D.,1967: Los Fenicios, Barcelona.

LE MEAUX, H. y SÁNCHEZ, M. D., 2007: «Le Mobilier non céramique», en P. ROUILLARD, E. GAILLEDRAT y F. SALA, L'établissement protohistorique de La Fonteta (fin VIIIe-fin VIe siècle av. J.-C.), Madrid, 319-337.
LORRIO ALVARADO, A., 2008: «Cuchillos», en M. ALMAGRO GORBEA, (dir.), La necrópolis de Medellín. II. Estudio de los hallazgos, Madrid, 566-571.

MAASS-LINDEMANN, G. 1995): «La necrópolis de Jardín. Catálogo», Cuadernos de Arqueología Mediterránea, 1, 65-213.

MANCEBO DÁVALOS, J., 2000: «Análisis de los objetos metálicos en el período orientalizante y su conexión con el mundo fenicio. Los cuchillos afalcatados», Actas del IV Congreso Internacional de Estudios Fenicios y Púnicos, vol. IV, Cádiz, 1825-1834.

MANSEL, K., 2000: «Los hallazgos de metal procedentes del horizonte fenicio más antiguo B1 del Morro de Mezquitilla (Algarrobo, Málaga)», Actas del IV Congreso Internacional de Estudios Fenicios y Púnicos, vol. IV, Cádiz, 1601-1614.

MAZAR, E., 2001: The phoenicians in Achziv. The Southern Cemetery, Cuadernos de Arqueología Mediterránea, 7, Barcelona.

MAZAR, E., 2004: The Phoenician family tomb $n .1$ at the nortern cemetery of Achziv (10 $0^{\text {th }}-6^{\text {th }}$ centuries BCE), Cuadernos de Arqueología Mediterránea, 10, Barcelona.

NIEMEYER, H. G., DOCTER, R. F ET ALII, 1998: «Excavación bajo el decumanus maximus de Cartago durante los años 1986-1995. Informe preliminar», en M. VEGAS (ed.), Cartago fenicio-púnica. Las excavaciones alemanas en Cartago (1975-1997), Cuadernos de Arqueología Mediterránea, 4, 47-109.

PELLICER CATALÁN, M., 2007: La necrópolis Laurita (Almuñécar, Granada) en el contexto de la colonización fenicia, Cuadernos de Arqueología Mediterránea, 15, Barcelona.

PISANO, G., 1988: «Las joyas», en S. MOSCATI, Los Fenicios, Barcelona, 370-393.

RUIZ DELGADO, M. M., 1986: «La fíbula de doble resorte en Andalucía (I): tipos y cronología», Habis, 17, 491-514.

RUIZ DELGADO, M. M., 1987-88: «La fíbula de doble resorte en Andalucía (II): aspectos mecánicos, origen y difusión», Habis, 18-19, 515-530.

RUIZ DELGADO, M. M., 1989: Fíbulas protohistóricas en el Sur de la Península Ibérica, Sevilla.

SPANÒ, A.,1995: «Aspetti inediti di cultura materiale dalla necropoli punica di Palermo», Cuadernos de Arqueología Mediterránea, 1, 33-53.

STERNBERG, M., 2007: «Pêche et exploitation des milieux aquatiques», en P. ROUILLARD, E. GAILLEDRAT y F. SALA: L'établissement protohistorique de La Fonteta (fin VIIIe- fin VIe siècle av. J.-C.), Madrid. 